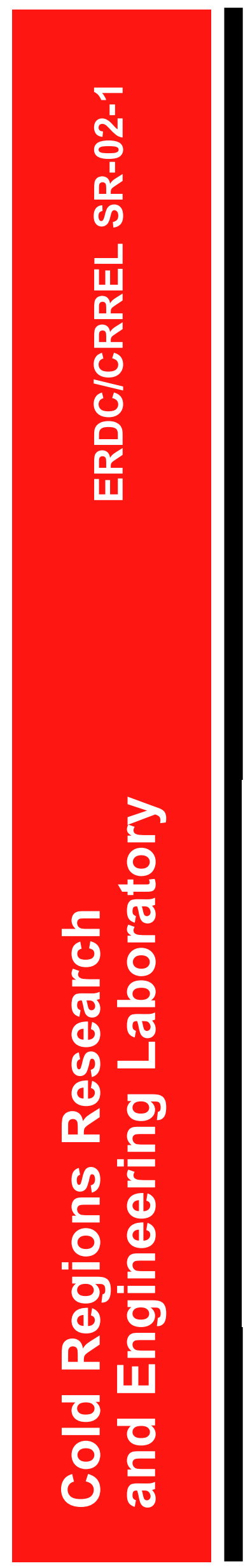

\title{
Snow and Ice Control (SNIC) Equipment and Its Use by Military Units Worldwide
}

Nicholas H. Collins

May 2002

US Army Corps of Engineers ${ }_{\circledast}$

Engineer Research and Development Center 
Abstract: When the U.S. Army moved into Yugoslavia in December 1995, it did so without snow and ice control (SNIC) equipment. The only available tools - the bucket loader mounted on SEE tractors, scoop loaders, full-track tractors, the M9 $\mathrm{ACE}$, and the motorized road grader-were not designed for SNIC. These tools are specialized and dedicated to specific missions, and attempts to use them for SNIC proved detrimental to both the equipment and the areas requiring snow removal. Upon receipt of an urgent call from HQUSACE, it was determined that a SEE tractor snowplow prototype had been designed by the manufacturer that built and produced the SEE's front loader bucket. Within six days, the company built a SEE snowplow and shipped it to Jericho, Vermont, where it was installed on a Vermont Army National Guard (ARNG) SEE tractor. The snowplow was tested in various scenarios, at various snow depths, at temperatures as low as $-15^{\circ} \mathrm{F}$. It performed better than expected and 17 SEE snowplows were sent to Task Force Eagle in Bosnia. Since then, snowplows for the 5-ton truck and HMMWV have been fielded to reduce the workload placed on the SEE tractor. The viability of using this equipment on various snow-covered terrain by soldiers from the 10th Mountain Division (Light Infantry) at Fort Drum, New York, and the Ethan Allen Training Center in Vermont, was demonstrated.

How to get copies of ERDC technical publications:

Department of Defense personnel and contractors may order reports through the Defense Technical Information Center:

DTIC-BR SUITE 0944

8725 JOHN J KINGMAN RD

FT BELVOIR VA 22060-6218

Telephone (800) 225-3842

E-mail help@dtic.mil msorders@dtic.mil

WWW http://www.dtic.mil/

All others may order reports through the National Technical Information Service:

NTIS

5285 PORT ROYAL RD

SPRINGFIELD VA 22161

Telephone (703) 487-4650

(703) 487-4639 (TDD for the hearing-impaired)

E-mail_orders@ntis.fedworld.gov

WWW http://www.ntis.gov/index.html

For information on all aspects of the Engineer Research and Development Center, visit our World

Wide Web site:

http://www.erdc.usace.army.mil 
Special Report

ERDC/CRREL SR-02-1

\section{Snow and Ice Control (SNIC) Equipment and Its Use by Military Units Worldwide}

Nicholas H. Collins

May 2002 


\section{PREFACE}

This report was prepared by Nicholas H. Collins, Physical Scientist, Military Programs Office, Applied and Military Research Branch, U.S. Army Engineer Research and Development Center (ERDC), Cold Regions Research and Engineering Laboratory (CRREL), Hanover, New Hampshire.

Funding for the majority of this work was provided by the Deputy Chief of Staff-Engineers (DCSENGR), Headquarters, U.S. Army-Europe, BG Donald Riley and his assistant, COL John C. Durkin; BG Steven R. Hawkins, the previous DCSENGR; and CPT Troy T. Schulz, DCSENGR, Project Officer.

The author acknowledges COL Gordon Wells, former Commander, 41st Engineer Battalion, 10th Mountain Division (Light Infantry), Fort Drum, New York, for assistance in conducting tests and demonstrations of the HMMWV snowplow at Fort Drum; and MG Donald Edwards, former Adjutant General, State of Vermont, MG Martha T. Rainville, current Adjutant General, State of Vermont, and COL Alan L. Nye, Vermont Army National Guard, for the use of personnel, equipment, and facilities in testing and demonstrating the SEE tractor snowplow and the HMMWV snowplow over a period of four years at the Ethan Allen Training Center, in Jericho, Vermont.

The author specifically acknowledges the direction, assistance, and support provided by LTC Mark C. Nelson, Commander, CRREL, 1994-1998, and Dr. Lewis E. Link, Jr., Director, CRREL, 1986-1996, both of whom were instrumental in initiating and partially funding the work reported herein, which was specifically intended to provide direct assistance to soldiers in the field and especially those in the Balkans.

The author gratefully acknowledges technical reviews by Dr. Ronald A. Liston and Dr. Paul W. Richmond, CRREL; field reviews by COL John C. Durkin, LTC Robert T. Morgan, and CPT Troy T. Schulz, USA, ODCSENGR, HQUSAREUR; and also acknowledges colleagues who contributed to the success of this effort, including, but not limited to, Dr. Stephen A. Ketcham, Paul V. Sellman, Michael R. Walsh, and Byron L. Young, CRREL.

This publication reflects personal views of the author as well as approved policy, practices, programs, and doctrine of the current snow and ice control program as it pertains to commercial off-the-shelf equipment and its usage by the U.S. Army. Contents of this report are not to be used for advertising or promotional purposes. Citation of brand names does not necessarily constitute an official endorsement or approval of the use of such commercial products unless so stated herein. 


\section{CONTENTS}

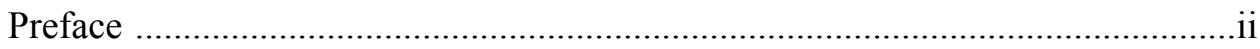

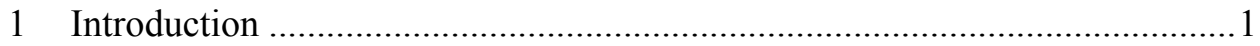

2 Snow and Ice Control (SNIC) Program ......................................................... 5

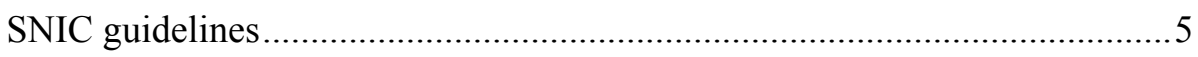

Levels of service and mission objectives..................................................... 5

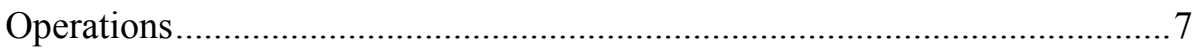

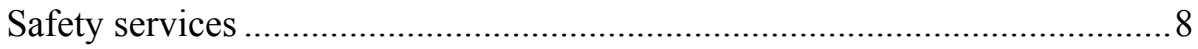

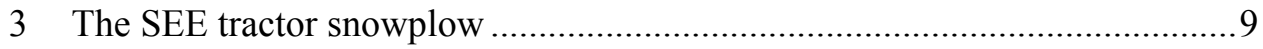

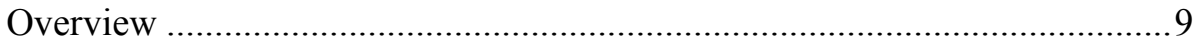

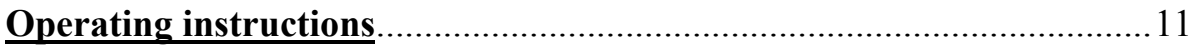

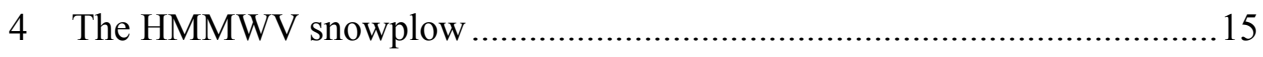

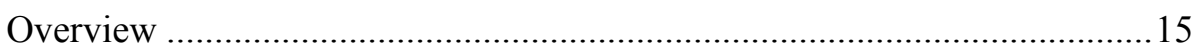

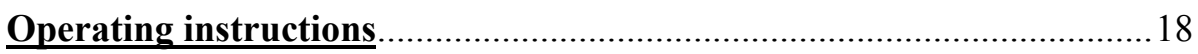

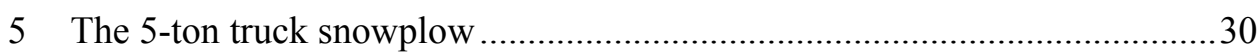

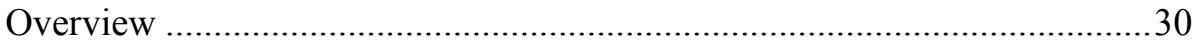

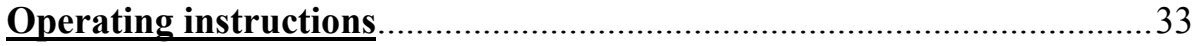

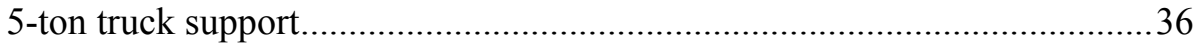

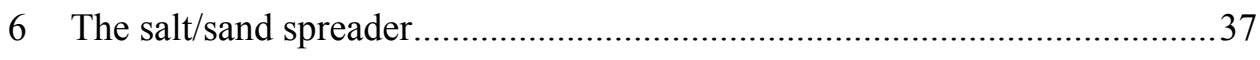

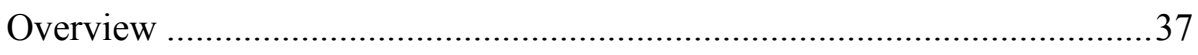

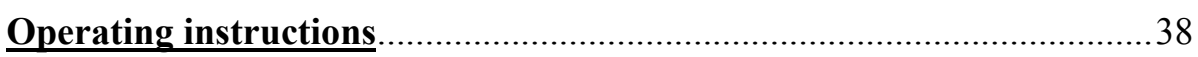

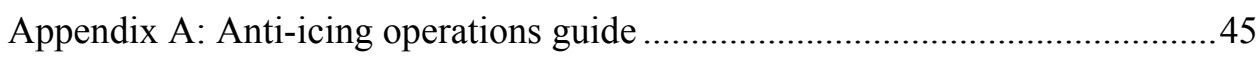

Appendix B: Cutting edge installation on the 5-ton truck snowplow ..................53

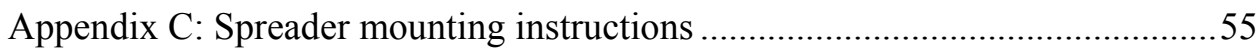

Appendix D: Wausau reversible snowplow for the 5-ton truck ..........................56

Appendix E: Ordering parts for commercial off-the-shelf (COTS) equipment ...60

Appendix F: HMMWV 8-ft snowplow with integral attachments.......................62

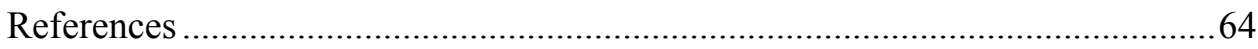




\section{ILLUSTRATIONS}

Figure 1. Seven-foot right-hand non-reversible snowplow mounted on a truck,

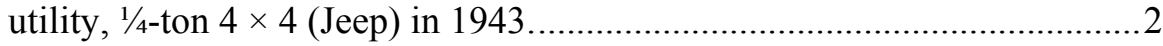

Figure 2. M34 2-1/2-ton, $6 \times 6$ dump truck manufactured by the Reo Truck Company in 1952-53 mounting a cable/hydraulic Roadway model 1d single-blade non-reversible 12-foot snowplow.

Figure 3. 1966 M35 $6 \times 6,2-1 / 2$-ton truck mounted with an early German-built Schmidt Engineering 11-foot conventional, manually reversible snowplow manufactured in 1950

Figure 4. Fifty-year-old Schmidt (of Germany) snowplow mounted on a Unimog tractor.

Figure 5. The SEE tractor is the most versatile snowplow in the U.S. Army inventory

Figure 6. Plowing steep grades uphill is not a problem for the SEE tractor and its 10 -foot fully reversible hydraulic plow

Figure 7. The author in Kosovo in 2000 inspecting HMMVW snowplows for necessary repairs and to conduct training....

Figure 8. HMMWV snowplow mounted on a HMMWV with chains on all four wheels

Figure 9. HMMWV with 9-foot plow, clearing snow from an access road .......19

Figure 10. HMMWV snowplow with mushroom installed incorrectly .............20

Figure 11. The HMMWV snowplow has proven to be an effective attachment and is in service in Europe and in the Far East as well as in CONUS .......26

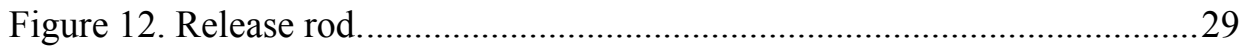

Figure 13. The 5-ton truck snowplow is manually reversible and hydraulically operated, 11 feet wide and 36 inches high.

Figure 14. Heavy-duty "Wausau" brand Schmidt snowplows being mounted on

5-ton trucks in Kosovo for use by U.S. Army Kosovo Forces (KFOR). ...32

Figure 15. Snowplows in Kosovo ready for installation....................................33

Figure 16. Wausau-brand snowplow manufactured by Schmidt Engineering and Equipment, Inc., of New Berlin, Wisconsin, mounted on a 5-ton truck....34

Figure 17. The author inspecting snowplows in Bosnia ...................................35

Figure 18. 5-ton truck with snowplow "cleaning up" after a major storm..........36

Figure 19. The 6-foot Henderson spreader was mounted on the M100 trailer at the request of commanders in Kosovo ....................................................40

\section{TABLES}

Table 1. Spreader application rate chart. 


\title{
Snow and Ice Control (SNIC) Equipment and Its Use by Military Units Worldwide
}

\author{
NICHOLAS H. COLLINS
}

\section{INTRODUCTION}

Upon learning that the U.S. Army required up-to-date snowplowing equipment to meet obvious demands after initiating operations into Bosnia in December 1995, the Commanding General, U.S. Army-Europe (USAREUR) asked the Chief of Engineers to provide expedited assistance to help resolve an urgent problem. The problem was given to the U.S. Army Cold Regions Research and Engineering Laboratory (CRREL), a U.S. Army Corps of Engineers asset, for immediate action.

The Small Emplacement Excavator (SEE) tractor had been through RDT\&E and fielding began in 3Q 1988. Shortly thereafter various additional attachments were in development to be substituted for the front loader bucket and the rearmounted backhoe. One of these was a snowplow to be mounted in place of the front loader. This work was ongoing in the late 1980s at the U.S. Army Belvoir Research, Development, and Engineering Center. After a prototype was developed, funding and command interest disappeared and the product was dropped. The prototype was lost but the paperwork was found, and a new plow was ordered from the original manufacturer, Schmidt Engineering and Equipment, Inc. Schmidt built the new plow from their drawings and delivered it to CRREL in six days.

The plow was put through severe tests and demonstrations both on and off road, on unpaved and paved roads, and on steep gradients. The plow passed all these tests and was declared fully operational. Seventeen SEE tractor snowplows were subsequently shipped to Bosnia.

The High Mobility Multi-purpose Wheeled Vehicle (HMMWV) snowplow was patterned after a similar plow that was developed for the commercial Hummer and first fielded to troops in Operation Able Sentry in Macedonia and to the 10th Mountain Division (Light Infantry) at Fort Drum, New York. This 
vehicle, with its attached snowplow, was put through various Army-required tests, one of which required snowplowing 1200 miles, and was eventually added to the Army inventory with a National Stock Number.

The 5-ton truck snowplow initially had been developed by TACOM and, although not being used at the time, was reviewed and redesigned to meet recent safety requirements, and retested at Fort Drum. Eleven of these snowplows were subsequently deployed to the Balkans and one remains at Fort Drum.

The need for a sand/salt spreader was obvious at the time and HQUSAREUR ordered the Henderson spreader deployed to the Balkans. CRREL reviewed three commercial spreaders based on a survey of the private sector and rank-ordered them at the request of USAREUR. The Henderson basic model was selected based on its versatility and the different sizes that allow it to be used on the HMMWV and the 5-ton truck. The different sizes are all powered the same and used in the same manner. The utility of conducting various applications of all of the snow and ice control (SNIC) equipment in realistic tests, in all kinds of weather, was successfully demonstrated.

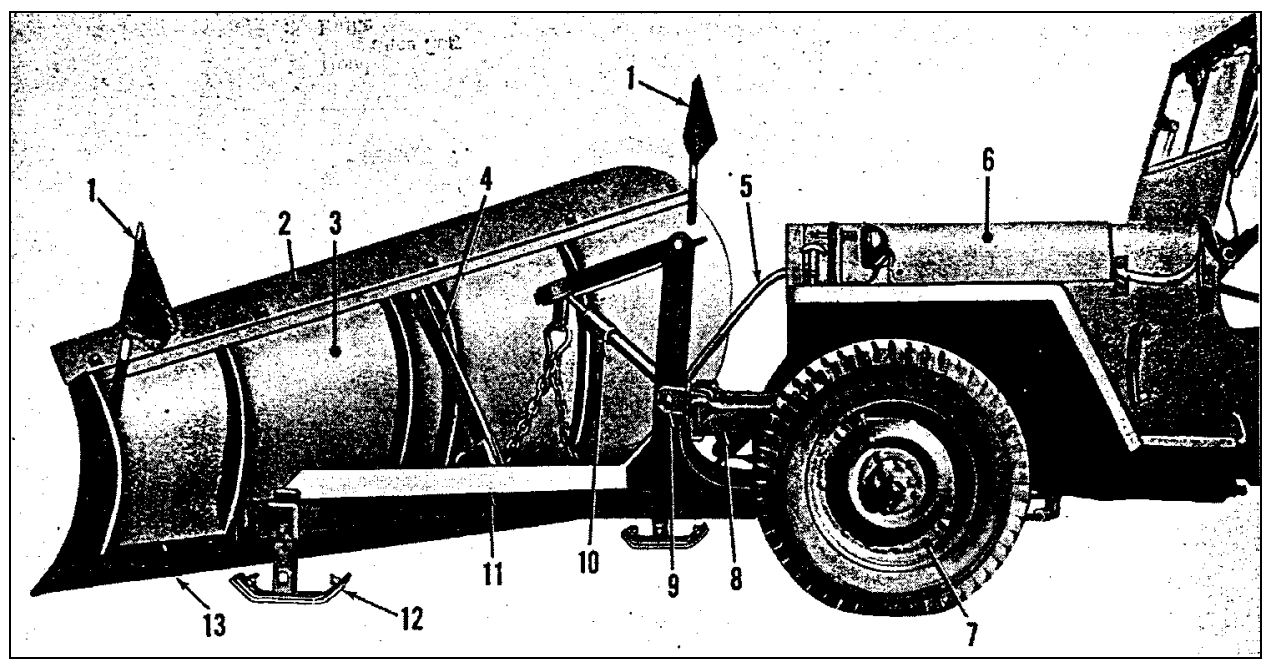

Figure 1. Seven-foot right-hand non-reversible snowplow mounted on a truck, utility, $1 / 4$-ton $4 \times 4$ (Jeep) in 1943. The single hydraulic cylinder, which raised and lowered the plow, was operated manually by the assistant driver from the assistant driver seat. This snowplow, though larger than necessary, was able to handle up to six inches of snow effectively.

Key:

1. Safety clearance flags 
2. Snow foil (originally called a baffle)

3. Moldboard

4. Main upright support strut

5. Hydraulic line

6. Hood

7. Front tire and wheel

8. Vehicle frame/bumper

9. Connection to bumper hitch

10. Hydraulic cylinder (ram-type)

11. A-frame support (push frame)

12. Skid shoe (plow shoe)

13. Cutting edge

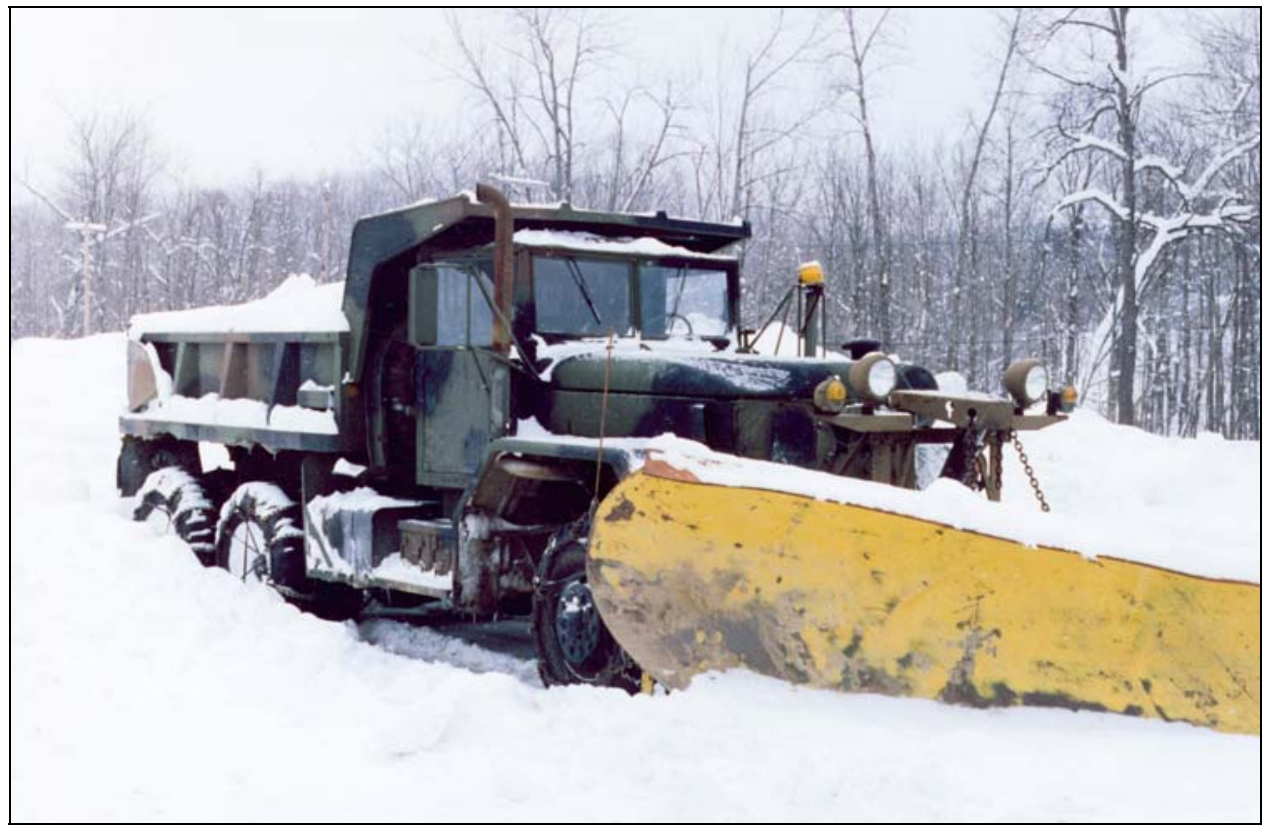

Figure 2. M34 2-1/2-ton, $6 \times 6$ dump truck manufactured by the Reo Truck Company in 1952-53 mounting a cable/hydraulic Roadway model 1d singleblade non-reversible 12-foot snowplow. The plow was manufactured in the 1963-66 time frame and is still in use today. 


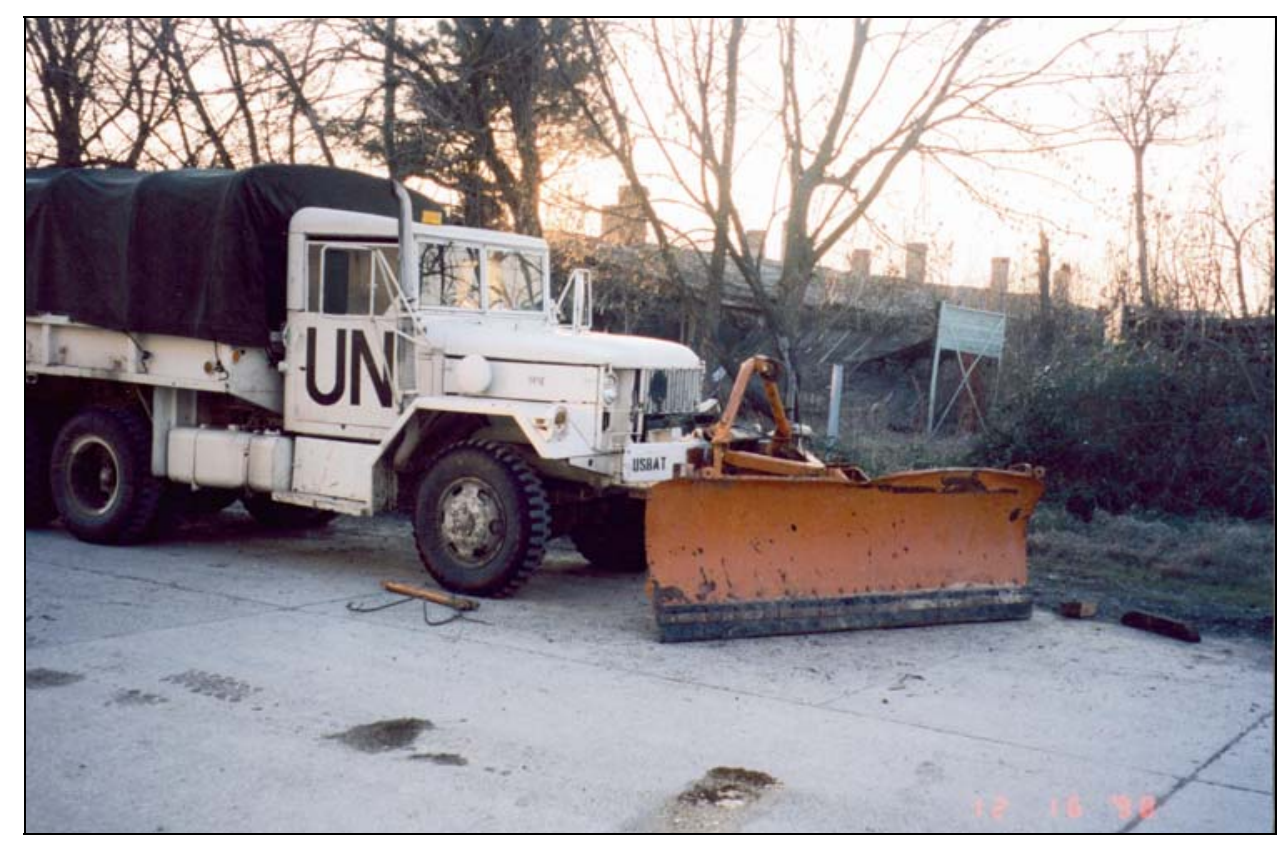

Figure 3. 1966 M35 $6 \times 6,2-1 / 2$-ton truck mounted with an early Germanbuilt Schmidt Engineering 11-foot conventional, manually reversible snowplow manufactured in 1950. This plow was in service in Baumholder, Germany, with the U.S. Army for 43 years before being shipped to Task Force Able Sentry in 1994, where it continues in service today.

Information: Operations instructions in this report were previously reviewed by the respective manufacturers and the Training and Doctrine Department of the U.S. Army Engineer School. The SEE tractor and the 5-ton truck snowplows were approved by TACOM. A prototype HMMWV snowplow had undergone initial testing by TECOM and the current model later was extensively reviewed for safety purposes and operational compatibility. This effort was completed and approved by TACOM in 1999. 


\section{SNOW AND ICE CONTROL (SNIC) PROGRAM}

\section{SNIC guidelines}

This chapter provides guidelines for the procedures that a Task Force Engineer or a Director of Public Works can use when contending with winter storms. It is understood that all winter storms are not the same and conditions can change several times during a single storm; therefore, flexibility is important in that guidelines are always subject to change in order to meet the mission objectives and the desired levels of service.

These guidelines serve to guide and protect the various units involved, at least to some degree, should a series of accidents occur during a winter storm.By outlining the mission objectives and the desired level of service that the units can strive to provide for those using the highways and roadways, a determination can be made as to whether the mission objectives and a reasonable level of accomplishment have been attained. If the mission objectives and the desired level of service cannot be met, these guidelines can be used to stipulate those conditions and the reasons why not. Although a disclaimer may not be important in field operations, it could be important on an installation where there are numerous commercial and privately owned vehicles.

These guidelines will help users understand what is expected of them and can provide an awareness of what level of service is to be expected during winter storm events.

\section{Levels of service and mission objectives}

There are four classifications of roads in SNIC operations. The level of service and the mission objective for each of these classifications appear below.

Caveat: It must be recognized that there can be situations when the level of service desired cannot be maintained and that the objectives desired cannot be achieved. This can be caused by equipment breakdowns, extremely severe storms with unacceptable risks, traffic tie-ups, and unsafe conditions, e.g., high winds, blowing snow, excessive icing, and whiteouts.

\section{Class $A$}

Major Supply Routes (MSRs) or similar designated highways (including Type X, STANAG 2174, all-weather route). These roads require continuous plowing efforts and salting applications as necessary, with the mission objective 
being bare pavement as soon as possible and practicable after the storm is over. Salting may be augmented with a liquid or solid anti-icer and/or deicer as necessary to reach the mission objective. Normally rock salt alone is effective only down to $22^{\circ} \mathrm{F}$, while additives may increase effectiveness down to $0^{\circ} \mathrm{F}$. Furthermore, with rock salt pre-wetted with calcium chloride liquid, $90 \%$ of the material stays on the road, whereas only $70 \%$ of the non-pre-wetted rock salt stays on the road.

Sand should not be used on paved road except during icy conditions below $22^{\circ} \mathrm{F}\left(0^{\circ} \mathrm{F}\right.$ if the salt material is pre-wetted $)$. Sand must be used on non-paved roads to alleviate slippery conditions, especially where grades exceed $3 \%$. An acceptable accumulation of snow on these roads would be two inches. A maximum average accumulation would be three inches. When the accumulation reaches four inches, snowplowing operations must begin and must continue until the storm stops and the roads have been plowed clean. Always plow with the storm. At no time is a Type-X road closed to traffic, except for severe weather, including temporary snow or flooding.

\section{Class $B$}

Alternate routes and those with steep inclines. These also are Type-X roads and include school bus routes as well as those providing access to emergency medical facilities. These routes should be continuously plowed except when prolonged storms may affect the ability of truck/snowplow drivers to operate safely. If a serious concern for safety should arise, operations should cease for a period not to exceed four hours. Salt and salt with enhancers should be applied as necessary on all roads designated as salt routes with the mission objective being bare pavement as soon as possible after the storm.

On non-paved roads the mission objective should be to provide sufficient sand to ensure reasonably safe driving conditions. During heavy snowfalls that could render sanding ineffective, sanding operations can be suspended until such time that the application of sand is effective. An acceptable accumulation of snow on these roads is two inches. The maximum average accumulation of snow must not exceed four inches.

\section{Class C}

These are Type-Y routes under STANAG 2174 and may not permit maximum-capacity traffic. These secondary roads and streets carrying light traffic should be plowed continuously during snowstorms to keep roads as clear as possible. During major storms it may not be possible to give these roads 
priority because of requirements on MSRs and alternate routes. Snowplowing vehicles should be reassigned to their original routes as soon as it is feasible to do so. Sanding can be limited to hills and intersections except when icy conditions require sanding operations. The objective here is to provide reasonably safe driving for a prudent driver. An acceptable accumulation of snow would be three inches. The maximum average accumulation of snow would be five inches.

\section{Class $D$}

These routes are Type S under STANAG 2174 and are seriously affected by weather. Lower traffic roads and side streets and roads and streets located in billeting/cantonment/residential areas should be plowed continuously during average storms if possible and practical to do so. If conditions are such that the other classes of roads cannot be adequately maintained, then equipment assigned to Class-D roads should be reassigned to meet the priority of other roads. The objective here is to provide reasonably safe driving conditions as soon as it is practical to do so. Sanding should be done only where and when needed. An acceptable accumulation of snow on these roads is four inches. The maximum average accumulation of snow is six inches. Such roads are considered fairweather roads, and if non-paved may become impassable with severe weather.

\section{Operations}

The normal material available to the various units for winter road maintenance includes sodium chloride (salt) and sand. These materials should be applied as shown in the tables in Appendix A. The amounts shown are the minimum; increasing amounts may be applied as necessary. Some units or locations may have calcium chloride $(\mathrm{CaCl})$ in liquid and/or solid form. Plowing during snowstorms should be continuous whenever possible until the storm abates or terminates. Upon termination of the storm, final plowing and cleanup should take place until the objectives have been met.

Calcium chloride in liquid or solid form will not be used when temperatures are $25^{\circ} \mathrm{F}$ or higher and are expected to remain there or rise. Common salt works well in this temperature range and does not need the addition of calcium chloride to be effective.

When the temperature drops below $25^{\circ} \mathrm{F}$, salt begins to lose its effectiveness and its action is significantly reduced. When the temperature is $25^{\circ} \mathrm{F}$ or lower, liquid calcium chloride (or other anti-icer or deicer) may be added to the salt at the rate of ten gallons per ton of salt. This increases the salt's action and lowers 
the freezing point of moisture on the road. Application of this mixture should continue as needed until the storm terminates.

When the temperature is $10^{\circ} \mathrm{F}$ or lower, application of these chemicals ${ }^{*}$ may be suspended because their effectiveness is degraded by the cold. The application of sand to increase or provide needed traction may be required; however, sand's effectiveness may be limited to the point where it is only of token assistance. Plowing should continue and the application of sand should be closely monitored and used as needed. If in doubt, spread the sand.

\section{Safety services}

During an average storm, conditions should be such that emergency vehicles are able to travel on all roads in the area of operations (AO). If difficult conditions arise, commanders should be prepared to advise safety services of any changes in the normal routine. If an emergency vehicle needs to respond to a call during a severe storm, the operator should notify the unit or post operations center. The supporting engineer unit or Directorate of Public Works can then assign the nearest available snowplowing truck to the emergency vehicle's route of travel to ensure that the responding emergency vehicle can reach its destination.

At some locations, the element providing snowplowing services will rotate vehicles to have one available at all times to meet emergencies should one arise. At the same time, such vehicles can be reloaded, refueled, and serviced as necessary, and operators can take a rest break.

\footnotetext{
* Other anti-icers and deicers may be available on the market. Most, however, are expensive to the point that they are not normally used on roads. Some recent improvements permit use of these melters with or without salt in temperatures as low as $0^{\circ} \mathrm{F}$. Lack of common usage is due to high cost, affecting availability in many areas.
} 


\section{THE SEE TRACTOR SNOWPLOW}

\section{Overview}

The Small Emplacement Excavator (SEE) tractor is a superb vehicle for plowing snow. It is used by many North Atlantic Treaty Organization (NATO) forces and is the vehicle of choice for plowing in the mountains of Germany. The SEE tractor is an upgrade to U.S. specifications of the German Unimog. Many soldiers find fault with the SEE; however, the SEE, if properly maintained and operated in accordance with the operator's manual, will provide excellent service, especially in SNIC operations.

The SEE tractor snowplow is manufacturer's model R3610 and National Stock Number (NSN) 3825-01-7801. This plow was developed from a commercial plow to fit the SEE tractor and is manufactured by Schmidt Engineering and Equipment, Inc., of New Berlin, Wisconsin. This is the same manufacturer that built the front loader for the SEE. Removing the front loader and replacing it with the snowplow is quite easy to do and takes less than 30 minutes when doing it outdoors in $0^{\circ} \mathrm{F}$. The front loader and the snowplow use the same connections, mechanically and hydraulically. The same action in the cab that raises and lowers the front loader will raise and lower the snowplow and the same action that tilts the front loader up or down will move the snowplow right or left.

The SEE tractor with chains correctly installed is the vehicle of choice for operations in the mountainous areas. In tests and demonstrations the SEE with snowplow was used in new snow, up to 10 inches, and in old snow up to 12 inches, both with varying percentages of snow density. It was used on paved roads, gravel roads, frozen organic soil roads, and on open fields with short grass, long grass, and tufted grass. With chains installed the SEE with snowplow was able to clear a 70- $\times 70$-meter helicopter landing pad in fifteen minutes. The area was covered with old snow up to 10 inches deep and topped with 4-6 inches of new snow.

During the test and demonstration phase at the Ethan Allen Training Center (EATC) in northern Vermont, the SEE tractor with snowplow was used on grades up to $12 \%$ with and without chains and traveling uphill and downhill in old and new snow. Over a period of five days the SEE tractor with snowplow plowed various types of snow in various depths up to 12 inches, accumulating 160 miles with and without chains. The vehicle performed without incident except for a small hydraulic leak in one hose on the plow. This was easily repaired by tightening the connection and replacing the lost fluid. 
The SEE snowplow was then taken to Fort Drum, New York, for further testing and demonstration by the 41st Engineer Battalion. During a 30-day period, with four snowstorms having depths of snow exceeding five inches, the SEE with snowplow accumulated another 124 miles. The SEE operated on hardsurface roads and hard-surface parking lots during this period, and it was easily determined that the success of the SEE was with chains installed. Only six miles of snowplowing was accomplished without chains. There were no problems with the snowplow, and a minor hydraulic leak at the interface between vehicle and plow was quickly and easily repaired by tightening.

It is highly recommended that chains be used on all four wheels at all times that snowplowing operations are being conducted.

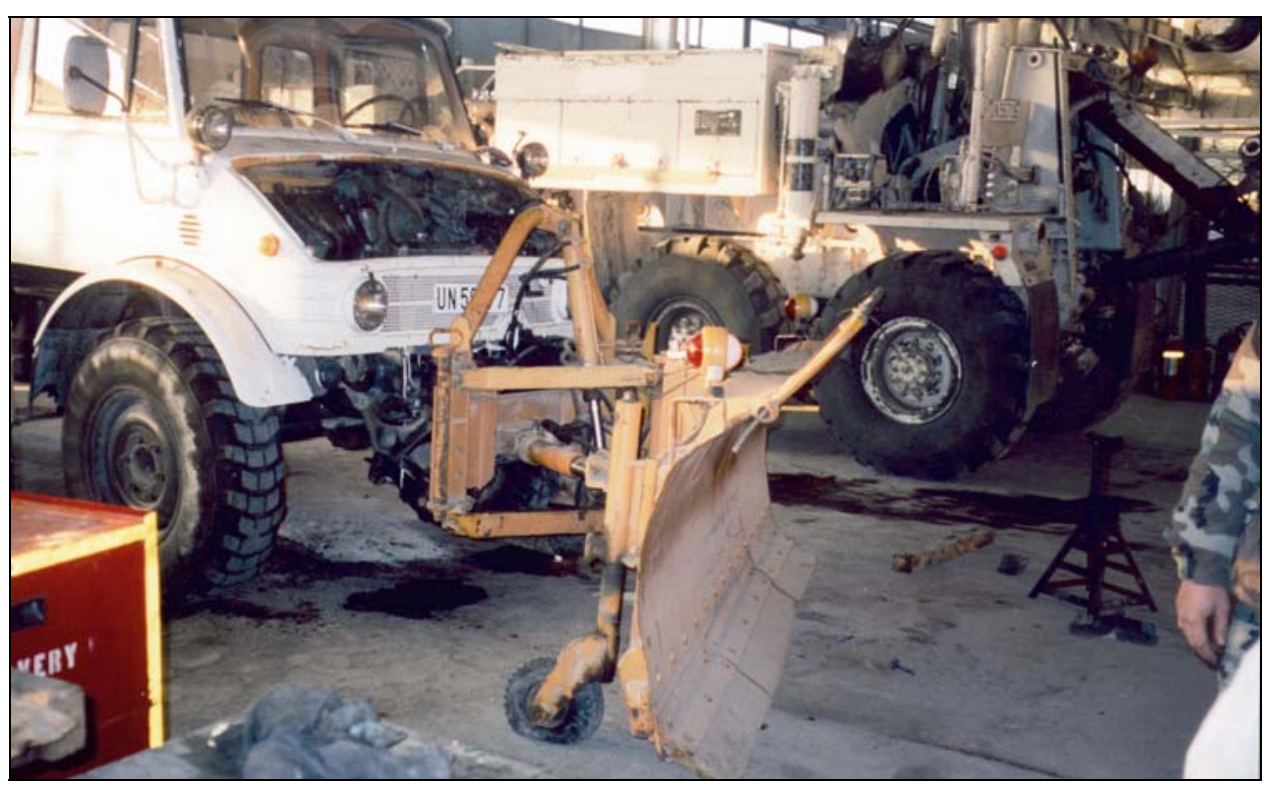

Figure 4. Fifty-year-old Schmidt (of Germany) snowplow mounted on a Unimog tractor. This snowplow provided quality service at Baumholder, Germany, for 43 years before being shipped to Macedonia. This fully reversible segmented snowplow with fully operational trip-edges still works well today. The Unimog is a sister vehicle to the SEE tractor that was manufactured in the United States by Freightliner Corporation. 


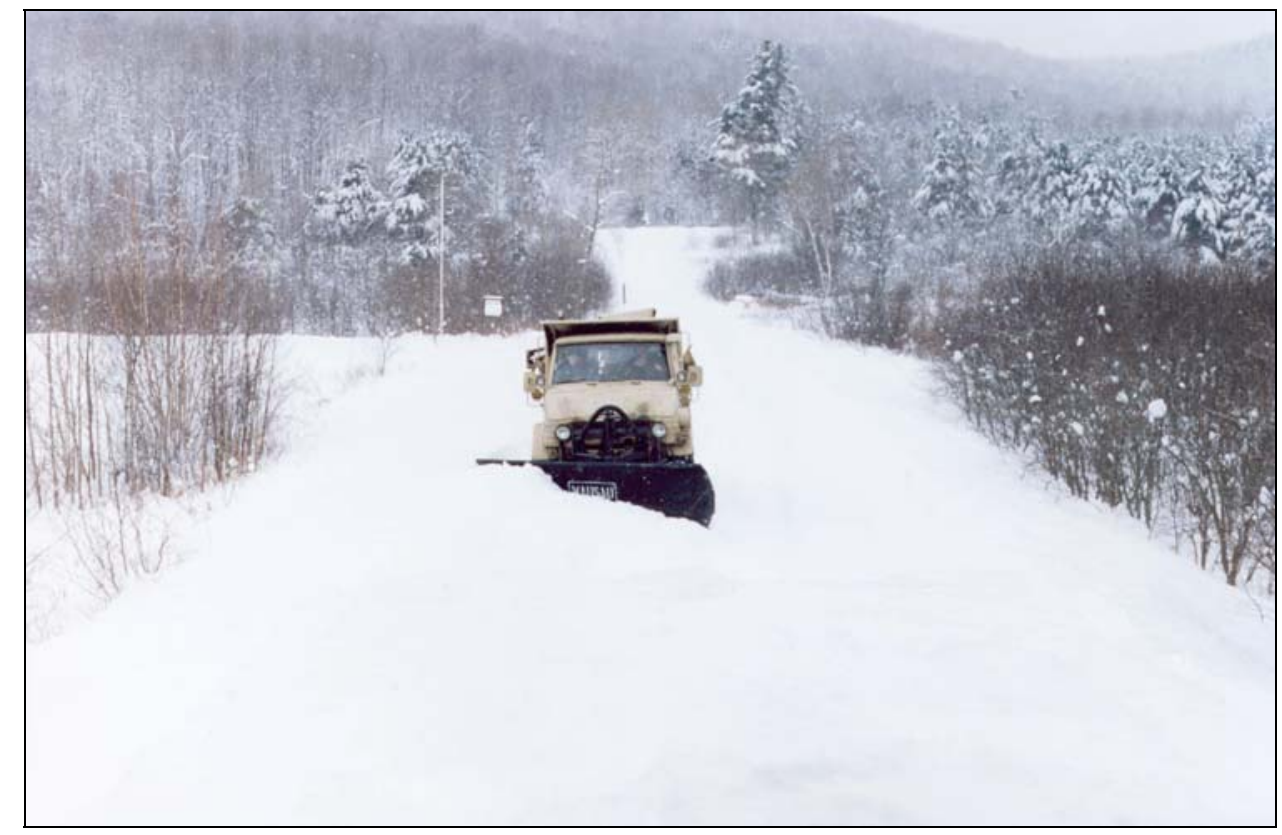

Figure 5. The SEE tractor is the most versatile snowplow in the U.S. Army inventory. It can plow off-road as easily as it plows paved and unpaved roads, staging areas, storage sites, or any other requirement. Such work requires that the SEE be maintained daily and be fully operational at all times.

\section{Operating instructions}

1. When plowing relatively smooth surfaces, let the blade "float." If the surface is uneven, lift the blade a half-inch or slightly more and then adjust for ongoing plowing. Experience will determine when it is best to raise the blade.

2. When plowing rough surfaces (such as open fields with clumps of grass) where the plow's trip-edge is constantly forced up, go slower and raise the blade often to allow the trip-edge to return to normal down position.

3. When pushing snow into a pile it is acceptable to have the plow face squarely towards the front. For all other plowing operations keep the plow up against either the right or the left stop. This reduces strain on the hydraulic system and maintains vehicle stability.

4. When plowing downhill maintain the same speed you would use for uphill plowing. If you hit a patch of ice you can greatly enhance braking ability by putting downward pressure on the plow. 
CAUTION: Too much downward pressure can cause loss of steering control.

5. Use tire chains at all times when plowing. The use of chains enhances control and provides added safety. Also, check to ensure that tires are mounted with tread in the proper direction.

6. When traveling over roads with the plow up and not in use, install the safety bar to prevent accidental drop.

7. Keep in mind the following safety tips:

(a) Slower is better than faster.

(b) When plowing a right-turn curve there are conditions that could force your vehicle to the left into oncoming traffic; when plowing a left curve and pushing snow to the left, certain conditions can force your vehicle to the right. These conditions include attempting to plow at high speeds, attempting to plow too much snow, icy surfaces, and a curb higher than the trip-edge.

8. If there appears to be too much snow, slow down and raise the blade; a second or third pass may be necessary to achieve a clean surface.

9. If the surface is icy, use chains on all four wheels. Also, ensure that tire pressure does not exceed the maximum recommended by TACOM (40 psi).

Under no circumstances should tire pressure be greater than the recommended 40 psi.

10. If tire slippage occurs because of deep snowplowing where the blade is slightly raised and 4-8 inches of snow remain on the road, lower tire pressure to 26 psi for added traction.

\section{WARNING!}

Do not drive the SEE over $15 \mathrm{mph}$ with tire pressure of $26 \mathrm{psi}$, even for short distances.

11. Maximum recommended plowing speed on hard-surfaced roads is 12 $\mathrm{mph}$; on secondary gravel or dirt roads, maximum recommended speed is 10 $\mathrm{mph}$. When plowing landing sites or open field areas, $5 \mathrm{mph}$ or less is the recommended speed. If in doubt in any situation, SLOW DOWN.

12. Be constantly alert to the area being plowed and to possible obstructions beneath the snow. If in doubt whether a curb or other obstacle is too high, raise the blade or steer around the obstacle, or both. If the obstruction is unknown, stop and investigate before proceeding. 


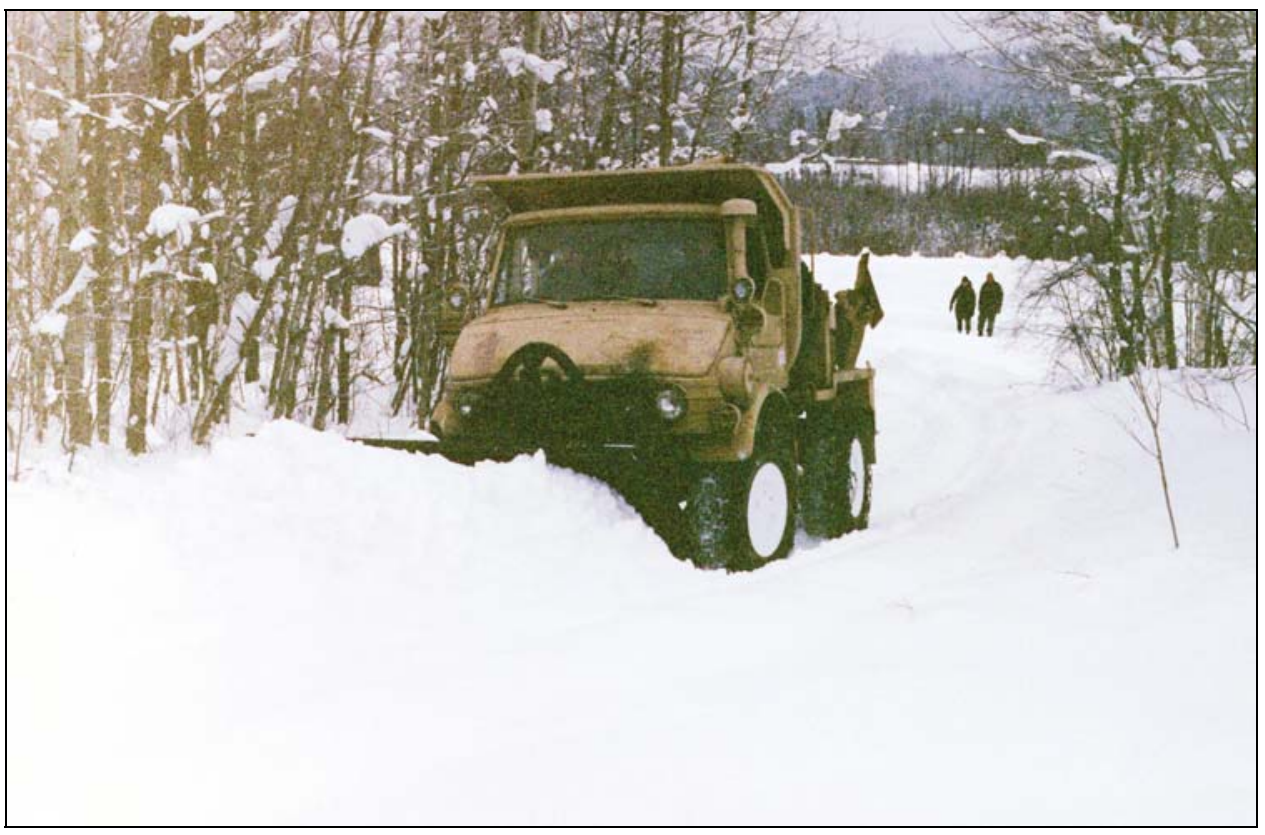

Figure 6. Plowing steep grades uphill is not a problem for the SEE tractor and its 10 -foot fully reversible hydraulic plow. Chains are required on all four wheels at all times to ensure traction and as a safety measure. The SEE tractor snowplow can be completely installed on the SEE in less than 30 minutes.

13. CAUTION: Do not attempt to plow mud or earth in any form. Attempts to do so will cause the trip-edge of the plow to trip into the "Up" position. The hinge section of the plow then becomes the cutting edge and in a very short distance the hinge and the trip-edge will be totally destroyed. Furthermore, hitting a stone or rock while operating without the functioning trip-edge can seriously damage the SEE and injure the driver.

14. Be alert to what is going on not only in front of the plow but immediately behind it - investigate any sign of a loss of hydraulic fluid and correct the problem at once.

15. Be aware that no "feet" ride behind the plow in contact with the surface. The trip-edge of this plow was designed to "float" along the surface being plowed. While in operation, this plow's storage legs (part \# 3200.1431) remain in the "Up" position. They are lowered only when removing the plow from the SEE and storing the plow when not attached to the SEE.

16. Always operate the plow angled fully against the stops to ensure stable plowing operations. 
17. Do not attack a snow bank or a furrow of snow at plowing speeds. Always reduce ground speed when applying a load to the plow. Start from a stopped position and slowly increase speed to effectively move the snow.

18. Adjust plowing speeds to existing road conditions - the more severe the road surface, the slower the plowing speed must be.

19. Never alter or defeat factory adjustments or materials on any safety device, such as the trip spring adjustment, shear bolt size, or the cushion valve adjustment. 


\section{THE HMMWV SNOWPLOW}

\section{Overview}

In the recent past, especially in troop units in U.S. Army Europe (USAREUR), the Army had limited access to snow removal equipment. The only pieces of equipment available were motor graders, the armored combat earthmover (ACE), and the front-end bucket loader on the small emplacement excavator (SEE). The SEE was designed with snowplowing capability, but snowplows for the SEE had not been approved and none were in the inventory. Also, the SEE was a scarce item and heavily used where deployed.

Because of the winter deployment of troops into Bosnia and earlier into Macedonia, HQUSAREUR requested a quick response to the problem, especially in Macedonia for Task Force Able Sentry (TFAS). At that time TFAS had a 1966 2-1/2-ton truck rigged with an old 10-foot snowplow that could still do yeoman service on local paved roads. TFAS also had a Unimog with snowplow; however, it performed marginally because of age and lack of maintenance. When it was operational, it performed effectively and efficiently. In addition to the truck and the Unimog, TFAS had a SEE with a very old German snowplow that worked well; however, there was a serious problem in keeping up with maintenance on the SEE tractor. In one 18-month period, the SEE was never operational due to problems of getting parts and performing maintenance.

In 1996, a special team was organized by HQUSAREUR to go to Macedonia to review requirements for the upcoming winter season. The TFAS commander requested a quick resolution to ensure safe, efficient, and effective snowplowing. HQUSAREUR (DCSENGR) asked the U.S. Army Cold Regions Research and Engineering Laboratory (USACRREL) to send someone proficient in snowplows and snowplowing, not only to help in determining problem solutions, but to be prepared to teach snowplowing operations and conduct hands-on training. All of these mission objectives were successfully accomplished.

USACRREL obtained a commercial off-the-shelf (COTS) snowplow specifically engineered for the commercial Hummer. The plow was manufactured by the Fisher Engineering Co., and the mount and on-vehicle components of the plow were designed and manufactured by Arrowhead Equipment, Inc. In a short period of preliminary testing it became obvious that such a combination worked well. It was further determined that the weight and size were compatible and the drive line components were well within the design range for a snowplow. 


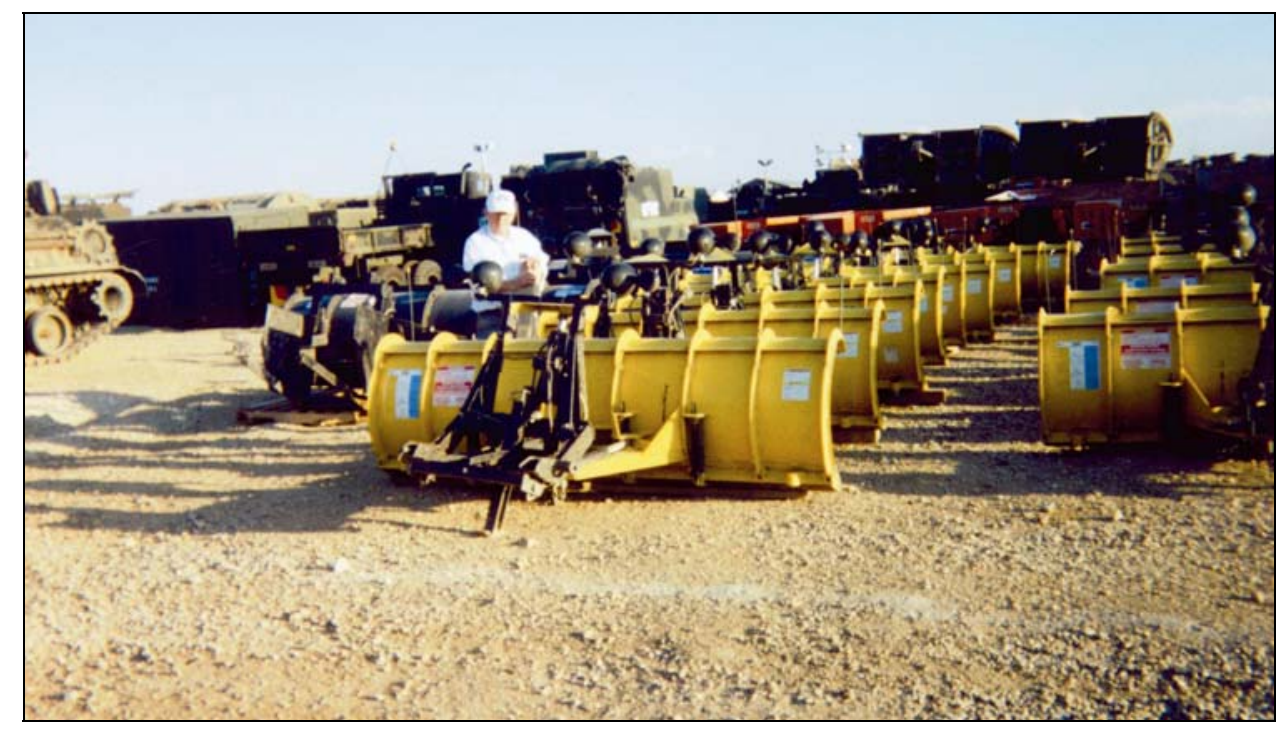

Figure 7. The author in Kosovo in 2000 inspecting HMMVW snowplows for necessary repairs and to conduct training. Note also the 5-ton-truck snowplows and sand/salt spreaders.

The plow uses a quick-connect and disconnect system called a MinuteMount (see Appendix F). Once the frame push-plates and the wiring harness, including the plow controller, have been semi-permanently installed on the HMMWV, the basic plow unit and all other attachments, including lights, directional signals, controlling pump and motor, in a single package, can be mounted and dismounted in less than a minute. The mounting frame push-plates do not normally require drilling, cutting, welding, or other modification on the HMMWV. Instead, bolt holes already in the frame and the bumper are used. The 24-volt wiring harness plugs into the current lighting harness and the power cable goes from a solenoid through the firewall to the battery. A controller cable is run through the firewall on the driver's side to the plow control switch, which is mounted on the dash with Velcro.

USACRREL had a complete snowplow set designed and made up for the M-998 series HMMWV. A plow was obtained by USACRREL, mounted on a HMMWV, and demonstrated and evaluated on hard-surface and gravel roads, trails, and off-road at the Vermont Army National Guard Ethan Allen Training Center in Jericho, Vermont. Snow depths averaged from four to nine inches in both new and old snow or a combination thereof. Snow density varied from light to heavy and the capability of the HMMWV with snowplow varied only slightly, and in all conditions was impressively successful. In accordance with data from previous studies, and common use throughout the industry, snowplowing opera- 
tions should always be conducted during the storm. Ideally, plowing should commence before snow depth reaches four inches to permit the greatest efficiency and effectiveness. Most installations and municipalities in CONUS begin snowplowing when the snow reaches three inches, and continue around the clock until the storm is over and the roads are bare.

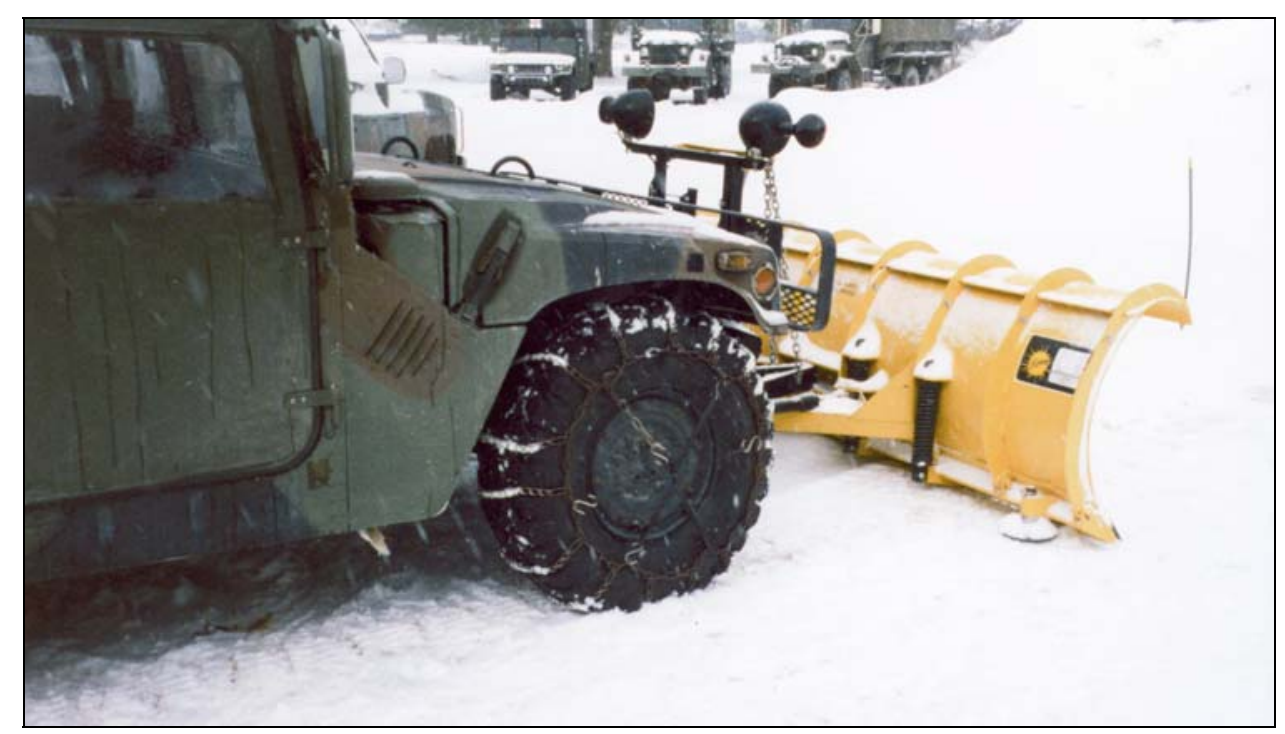

Figure 8. HMMWV snowplow mounted on a HMMWV with chains on all four wheels. This snowplow can be mounted and dismounted in less than a minute after the on-vehicle frame push-plates and the wiring harness are installed.

The 9-foot by 29-inch, 11-gauge steel, trip-edge snowplow was initially purchased with a continuous curve snow foil and a 1090 high-carbon steel cutting edge. The pump, hydraulics, headlight, directional lights, and attaching A-frame hardware are integral to the plow, as are the trip-edge and the trip-edge springs. This heavy-duty snowplow is commonly used on commercial light, medium, and heavy-duty series pickup trucks and light trucks up to two tons.

The plow has a fully reversible angle capability of 28 degrees to the right and left; and it has up (10 inches) and down capability, all of which can be controlled from the driver's position in the cab. The plow also has an integral trip-edge that folds back and allows the plow to ride over obstacles up to four inches high. When the obstacle is cleared, spring tension is released so that the cutting edge returns to its normal plowing position.

During testing of the snowplow in various scenarios, 450 pounds were loaded into the back of the HMMWV; however, no significant advantage was 
observed even when plowing uphill. The practice of adding weight up to a maximum of 450 pounds is neither encouraged nor discouraged; however, any weight in the back of the HMMWV, including sandbags, must be secured. Follow-on tests showed that the use of tire chains provided additional traction both uphill and downhill, as well as on varying terrain, and greatly reduced the incidence of tire spin. The use of tire chains on the HMMWV when conducting snowplowing operations should be mandatory. The only major changes since early $R \& D$ has been reducing the snowplow to the eight-foot-length and fully converting the components to 24 volts.

At present, there are more than 160 HMMWV snowplows being operated by the U.S. Army. As of 15 March 2002, more than 4000 snowplowing miles during five winter seasons had been accumulated without serious maintenance or operational problems on a test model. The most serious problems are caused by untrained drivers and incidences of trying to plow snow at speeds over $10 \mathrm{mph}$. A third serious problem is attempting to stack snow without the snow foil in place and trying to push snow after it has been stacked. Such work is not valid for the HMMWV. If the snow has been stacked and it is later decided to move it or push it back even more, do not use the HMMWV; use a machine with a front loading bucket.

At the request of the Commanding General, U.S. Army Engineer School, the HMMWV is now available by using National Stock Number (NSN) 3820-01473-2777, and it can be ordered through regular supply channels to the Defense Supply Center-Philadelphia (DSC-P).

\section{Operating instructions}

1. The Fisher L-Series snowplow is a heavy-duty snowplow usually equipped with a snow foil and a steel cutting edge that enhances the overall capability of the snowplow and helps provide for a longer service life. The blade has a unique trip-edge and is backed with wear-resistant bars. Special wear-bars are welded at the corners behind the base angle. The location of the moldboard bottom bar makes this particular blade tougher and helps to ensure long effective service.

2. The trip-edge is a highly functional safety feature of this particular blade. When it encounters an obstacle, only the edge trips, not the entire blade. Because the blade remains upright, the snow in front of it stays put, the load is not dumped, and continued plowing is possible without interruption. 


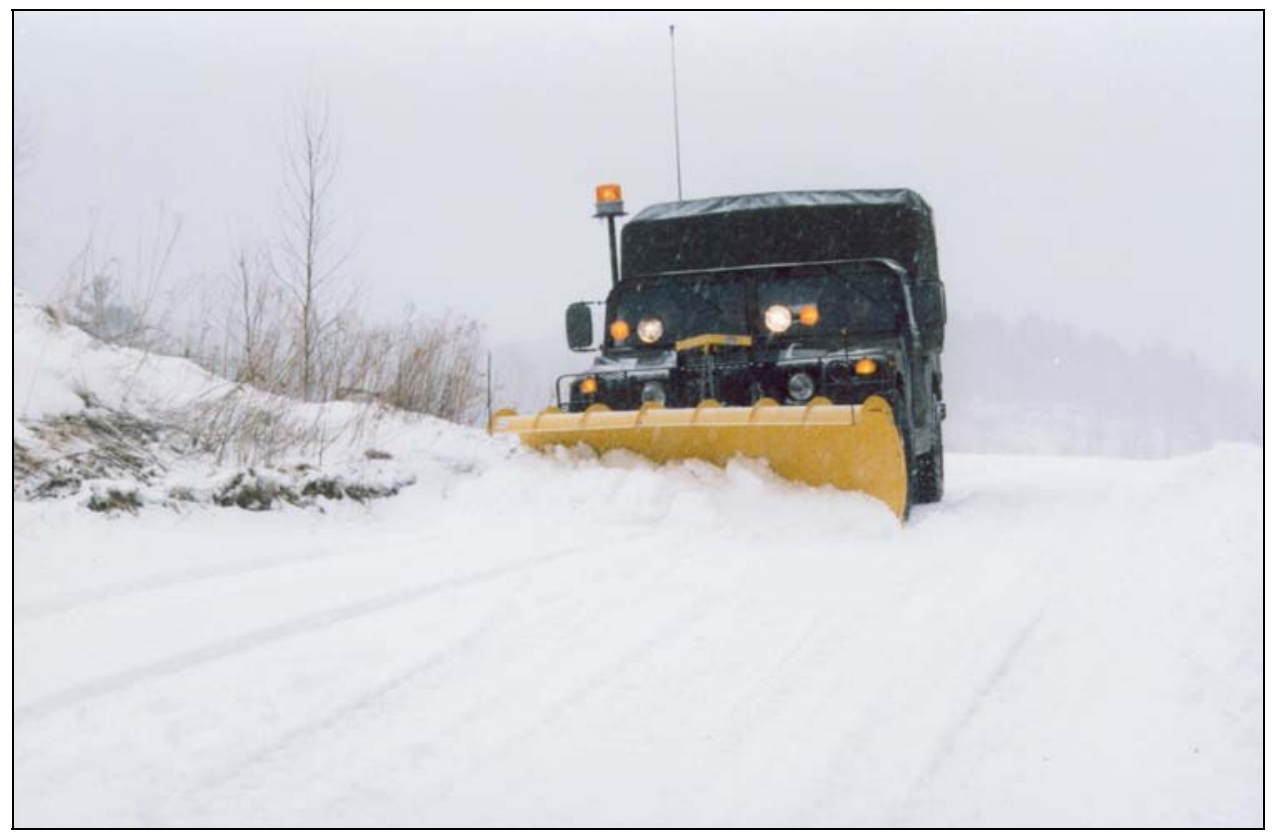

Figure 9. HMMWV with 9-foot plow, clearing snow from an access road. The early snowplows were 9 feet wide and worked very well; however, to improve safety, since 2000, all HMMWV plows are 8 feet wide. This plow is fully reversible and has an automatic trip-edge.

3. The snow foil (called a Snofoil by the manufacturer) is a rigid extension to the snowplow blade that deflects light snow away from the HMMWV's hood and windshield, thus improving plowing visibility, efficiency, and control.

4. Antiwear shoes, also called disc shoes or mushroom shoes, offer maximum protection against blade wear. The more the blade is used, the more important the shoes become. They should be adjusted to exactly the same level as the cutting edge.

5. The snowplow is connected to the HMMWV by an attachment kit composed of an A-frame, upper and lower gear, jack, and lift arm. The A-frame is attached to the blade assembly with a center pivot pin that allows the assembly to be angled left or right 28 degrees. The upper and lower gears and lift arm are the primary link between the plow and the HMMWV. The upper and lower gears are connected to the push-plates, which are bolted directly to the vehicle frame. The upper gear provides the mounting framework for the Solenoid Electric Hydraulic Pak (SEHP) and lift arm. The lift arm raises and lowers the blade through the lift cylinder and lift chain. 


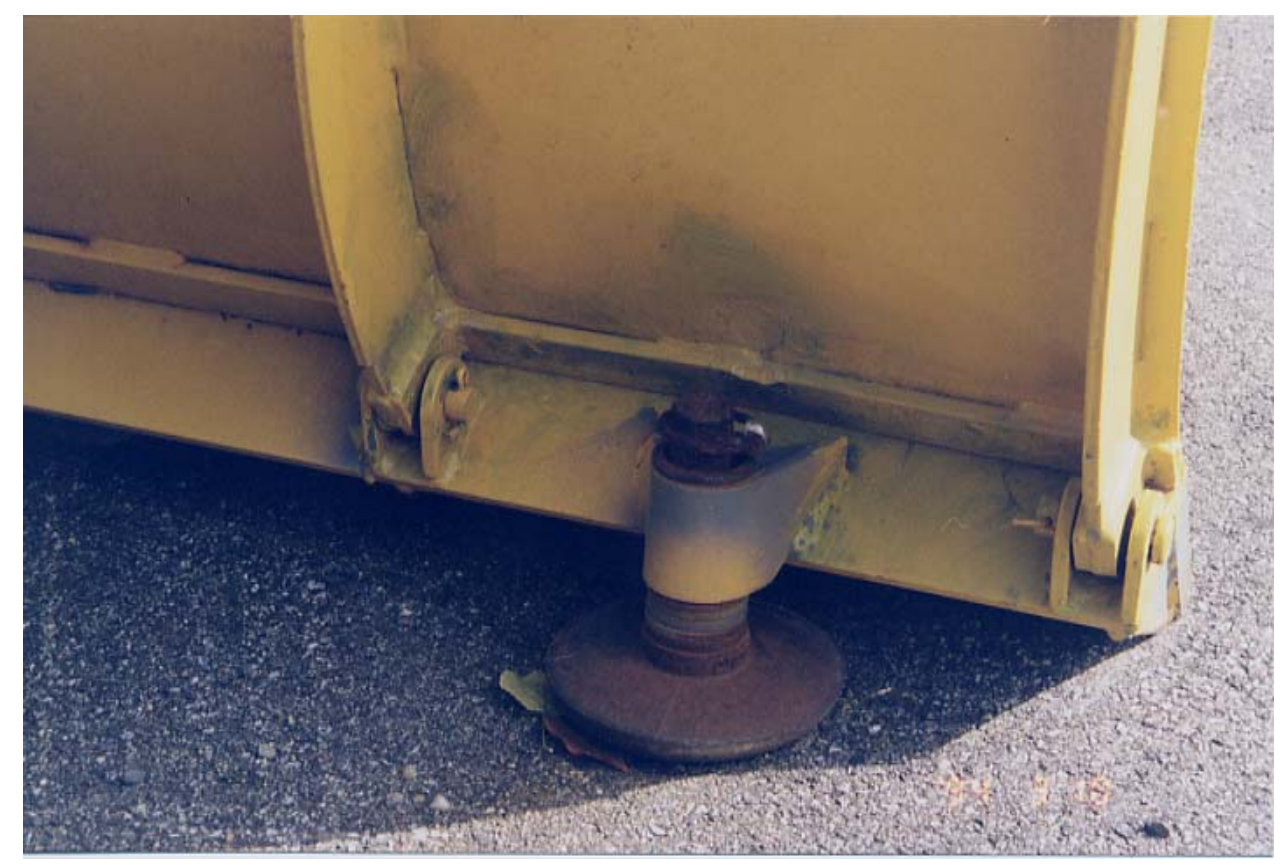

Figure 10. HMMWV snowplow with mushroom installed incorrectly. The shoe should be installed with sufficient spacer rings between it and the mounting bracket that permits the bottom of the shoe to be at the same level as the plow's cutting edge. Excess spacers should be tied on a string or wire and stowed in the vehicle; they should not be installed on the shoe shaft above the bracket as shown here. Doing so prevents the shoe from sliding on the shaft if the trip edge is deployed, thus causing the shaft to hit the back of the plow and eventually punching a hole in it.

6. The plow lights include a set of dual-beam headlamps and combination park-and-turn signals. When both plow plugs are connected during plow installation, the headlights, when turned on, will automatically switch to the plow lights. When the plow plugs are disconnected during snowplow removal from the HMMWV, power will automatically switch back to the vehicle headlights.

7. The Minute-Mount System is an attachment kit designed to fasten to the front and the front sides of the HMMWV frame. It is engineered to provide the primary connecting points between the snowplow and the vehicle. The weight of the Minute-Mount System is distributed directly to the frame of the HMMWV. When plowing, the forces on the snowplow are transmitted directly to the Minute-Mount System and from there to the vehicle frame. When plowing or when parked with the plow in the full down position, all the weight of the plow is on the ground. 
8. The joystick control is electrically powered through the HMMWV's ignition switch and is protected by a replaceable six-amp in-line fuse. The "On/Off" switch can turn off the control and prevent blade movement even when the ignition switch is in the "On"position.

9. The Solenoid Electric Hydraulic Pak (SEHP) provides a fast and uniform speed for lifting and angling. It takes only $2-3$ seconds to lift and lower the blade, and it angles from side to side in 5-6 seconds. The SEHP provides power lifting and angling with plow control from inside the cab.

\section{WARNING!}

You can be seriously injured if the blade hits you or drops on you. Keep well clear of the blade when it is being raised, lowered, or angled. Do not stand between the vehicle and the blade or directly in front of the blade.

\section{WARNING!}

Hydraulic oil under pressure can cause serious injuries that, if left untreated, can result in amputation or death. If you are injured by hydraulic oil, get medical treatment immediately.

\section{WARNING!}

Before traveling with the plow in the "Up" position with the safety chain in place, position the blade so that it does not block headlight beam. Do not change blade position while vehicle is in motion.

10. Controlling the blade is easily accomplished. First, turn on the vehicle ignition switch, then turn the control switch to the "On"position. The control switch is located on the side of the joystick control box. When the switch is on, the control indicator light should be on.

11. To raise the blade: Place the joystick control in the "Raise" position until blade has reached the desired height. Blade movement will stop when either the control is released or the blade reaches its upper limit.

12. To angle the blade to the right: Place the control in the "Right" position. Release the control when the desired angle is reached. The blade will stop when it reaches 28 degrees of angle and hits the right blade stop; if this happens, release the control.

13. To angle the blade to the left: Place the control in the "Left" position. Release the control when the desired angle is reached. The blade will stop when it reaches 28 degrees of angle and hits the left blade stop; if this happens, release the control. 
14. To lower and float the blade: Moving the control lever to the "Lower" position will automatically lower the blade to the surface and actuate the "Float" mode.

15. "On/Off' switch: Remember, sliding the control power switch to the "On"position activates the hydraulic system. Sliding the control power switch to the "Off"position will lock the blade in place, preventing accidental blade movement.

16. Before conducting operations with the plow attached to the HMMWV, double-check the plow lights. With both power cable plugs connected, check the proper functioning of all vehicle and plow lamps as follows:

- Parking lamps: Both vehicle and plow parking lamps should be on.

- Right turn signal: Both vehicle and plow right-turn lamps should be working.

- Left turn signal: Both vehicle and plow left-turn lamps should be working.

- Headlights: With the vehicle headlamp switch on, connecting and disconnecting the plow harness power plugs should switch between the vehicle and plow lamps as follows:

- Plow power plugs disconnected - only vehicle headlights work.

- Plow power plugs connected-only plow headlights work.

Note: The plow power cable plugs need to be connected to the grille connector receptacles for the plow lights to function.

\section{WARNING!}

Make sure the blade does not block the plow headlight beams.

17. When first installing the plow, aim plow lights with the plow mounted and raised to the travel position. Aim vehicle headlights with the plow removed from the vehicle.

Note: When plow headlights are on, vehicle headlights should be off.

18. When parking the HMMWV with the plow attached, lower the blade to the ground. If soil is soft or if there is standing water, rest the blade on pieces of lumber if possible to keep the blade from freezing to the ground.

\section{WARNING!}

Always lower the blade fully when the vehicle is parked. Failure to do so can result in serious injury. Temperature changes can change hydraulic pressure, 
causing the blade to drop unexpectedly. Also, any damage to hydraulic components can cause unexpected blade drop.

\section{WARNING!}

When transporting the plow in the "Up" position, always drive within posted speeds or within the vehicle recommended speed, whichever is lower. Reduce speed in poor weather conditions or when driving on uneven surfaces, such as railroad crossings or bumpy roads.

19. If the plow hits the ground while driving it in the up-travel position, serious damage can occur to the plow and vehicle. Use extra caution when transporting the plow in this manner to ensure safe operations at all times. If in doubt in any situation or under any circumstances, double-check all connections. When resuming travel, do so at lower speeds. If in doubt, go slower.

\section{WARNING!}

With the plow installed, the HMMWV must be equipped with plow lights and directional lights. Be sure these lights or operating properly before traveling.

20. When traveling with the snowplow in the "Up" position, do the following:

- Raise the blade.

- Adjust blade and carrying chain for maximum plow headlight illumination.

- Move joystick “On/Off” switch to "Off"position to lock blade in place.

- Monitor vehicle operating temperature. Overheating is unlikely under normal driving conditions. Occasionally, the plow may deflect air away from the radiator. If this occurs, stop the vehicle and raise or lower the plow slightly to correct overheating.

Note: These instructions are for driving short distances to and from plowing operations. For long trips, remove the plow from the vehicle.

\section{WARNING!}

Always wear seat belt when plowing snow. Hidden obstructions can cause the vehicle to stop suddenly, injuring the driver and assistant driver. Do not plow with anyone riding in the back of the HMMWV. 


\section{WARNING!}

Never put your head out of the window while plowing. Sudden stops or protruding objects can cause serious injury or death.

\section{WARNING!}

To prevent damage to plow or HMMWV, flag or otherwise mark any known obstructions that are hard to locate.

21. Before plowing snow, make yourself aware of any possible obstructions hidden beneath the snow, such as bumper stops in parking lots, curbs, walkways, sidewalks, shrubs, fencing, rocks, and other protruding objects. Make every effort to become familiar with the area you may be called on to plow.

22. If at all possible, plow during the storm rather than let the snow accumulate. As a general rule of thumb, plow before four inches of snow accumulates.

23. When plowing staging areas, parking lots, or helipads, if you want to stack snow, begin raising the blade as you come close to the stack. This will let the blade ride up the stack.

\section{WARNING!}

If attempting to clear a helipad, be certain that the area is sufficiently large to accommodate the largest helicopter with ample room to permit all clearances. Do not stack snow high enough to endanger the helicopter blades.

24. Certain conditions require various skills and techniques to plow successfully.

- Hard-packed snow

Raise the disc shoes on the blade high enough so that the cutting edge comes into direct contact with the pavement.

Use the lowest gear to place maximum force behind the cutting edge.

Angle the blade; it is more effective for removing hard-packed snow.

- Deep snow

Raise the blade 3-4 inches and try shearing off top layers for the initial pass.

Using only partial blade width, bite into the edges until the job is cut down to size for full-blade plowing. 
Note: 6 inches of snow may be plowed with the entire blade width, 9 inches with $3 / 4$ blade width, and 12 inches with 1/2 blade width. Experience and "feel" are the best guides; however, if in doubt, slow down and plow less snow until a clear path is established.

When plowing deep snow, keep the vehicle moving. (If stopped by deep snow you may have to back up and raise the blade and/or attempt a smaller cut using less width of the plow.)

25. Although the HMMWV has plenty of power for snowplowing operations, there is always the possibility of losing traction. Use tire chains in deep snow, or when operating on hills, or when slippery conditions exist or may exist. Install the chains with tire at maximum inflation pressure; readjust to ensure tightness after operating approximately $2 / 10$ of a mile and then reduce tire pressure to lowest inflation pressures allowable (see HMMWV Operators Manual). This ensures that chains are snug and provides optimum traction.

26. Counterbalancing may help to provide maximum traction. Any counterbalancing material, (sand, sand bags, blocks, drums, etc.) must be solidly secured to the vehicle to prevent it from moving under harsh plowing conditions. For the HMMWV, the maximum allowable added weight is 900 pounds. It appears from tests and experience that, under most conditions, counterbalancing is not necessary. Tire chains should be the primary method of traction enhancement for all conditions. Counterbalancing with 450 to 500 pounds could be useful in unusual conditions of snow and ice; however, chains are always required.

27. When clearing small access roads or driveways, do the following:

- Head into the driveway or access road with the blade angled and plow the snow away from any buildings. Widen the driveway or roadway by rolling the snow back with the blade angled to its maximum.

- If a building is at the end of the driveway, plow to within a vehicle length of the building. Push as much snow as possible off the driveway.

- With a raised straight blade (no angle on the blade), drive through the remaining snow to the building; drop the blade and "back-drag" snow away from the building for at least one vehicle length. Repeat as necessary to clean the snow away. Then back the vehicle to building and plow forward, removing the remaining snow from the driveway. 


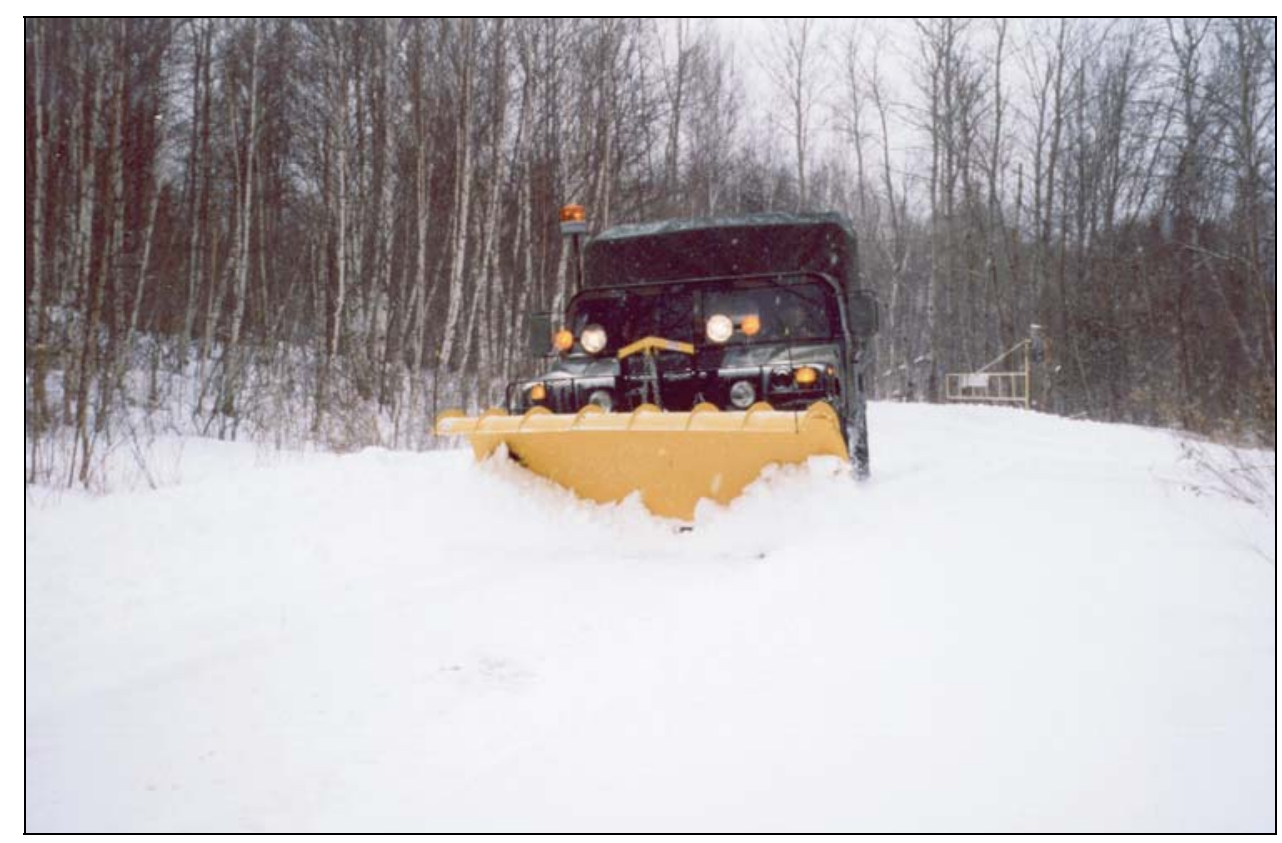

Figure 11. The HMMWV snowplow has proven to be an effective attachment and is in service in Europe and in the Far East as well as in CONUS. It is an 8-foot, hydraulically operated plow capable of plowing MSRs and various classes of roads and highways. For safety purposes, the maximum allowable speed while snowplowing is $10 \mathrm{mph}$.

28. When clearing parking lots, staging areas, etc., do the following:

- Clear areas in front of buildings first. Drive up to the building with the blade raised; drop the blade, and "back-drag" the snow away from the building. When the snow is away from the buildings, turn the vehicle around and push the snow out of the way.

- Plow a single cleared path down the center in the long direction.

- Angle the plow toward the long sides and begin plowing successive strips lengthwise until the area is cleared and snow is stacked around the outer edges.

- If snow is too deep to clear in the above manner, clear main traffic lanes as much as possible and stack the snow in windrows in such a manner as to provide greatest available space.

29. When plowing snow from Main Supply Routes (MSRs) or heavily used access roads, observe the following at all times: 
- For best results always plow with a storm. Do not allow more than four inches of snow to accumulate before starting plowing operations. The snowplow works easier and the end results (cleared driving surfaces) are obtained at lower costs.

- Be familiar with roads before plowing. Hazards such as curbs, raised traffic control bumps, sharp curves, guard rails close to the road, etc., need to be fixed in the driver's mind.

- Do not exceed $10 \mathrm{mph}$ while plowing. (Under no circumstances should vehicle speed exceed $10 \mathrm{mph}$ while plowing. This includes long straight paved roads with guideposts, a slight downgrade, and no one else on the road.) Under any unusual circumstances or if you have any question about hazards, SLOW DOWN. If necessary, get out of the vehicle and investigate what may be in or under the snow. There is no good excuse for taking chances and putting the vehicle, the plow, or people at risk. If necessary, do not exceed $5 \mathrm{mph}$.

- When plowing hills the preferred method is to plow uphill first, using the lowest possible gear, then plow downhill; this is especially true for steep hills. Maintain a smooth forward motion. On hills or steep grades, control is the important aspect of the task at hand and there is considerably more control plowing uphill versus plowing downhill on the first pass. If there are under-snow icy conditions a sand truck can follow the snowplow to spread sand. This will provide traction for both vehicles when descending that same steep road. When snowplowing down the hill, the HMMWV can have the left front and the left rear tires on the sanded portion of the road even while plowing down the hill.

\section{CAUTION!}

- Always drive slowly and cautiously while blade is attached.

- Always attach carrying chain for over-the-road travel.

- Always lower the blade when the vehicle is left unattended.

- Always remember that snowplowing is hazardous.

- Always use tire chains on all four wheels when plowing.

30. Pre-operational checks are required for safe operations:

Check that all fasteners, mounting bolts, hydraulic, and electrical connections are tight. Also check all plugs and seals for leaks and repair as necessary. Look especially for cracked or damaged hydraulic lines. Replace worn or defective parts. Check all lights. 


\section{WARNING!}

Never attempt to plow mud or dirt in any form at any time; serious damage to the equipment and personal injury can occur.

Note: A training video, Snowplow Operations with the HMMWV, with an added feature, Tire Chains: How to Install and Use Them, is available from the U.S. Army Cold Regions Research and Engineering Laboratory (USACRREL), ATTN: Library Services, 72 Lyme Road, Hanover NH 03755-1290.

31. Once the HMMWV has the frame plates and wiring harness with the plow controller installed, the plow properly assembled can be easily mounted on and dismounted from the HMMWV. Instructions for doing this are found on the back of the snowplow blade. These instructions are detailed and cover mounting the plow and dismounting the plow. For safety purposes and for correct usage, these instructions should be followed exactly as described.

\section{WARNING!}

Inspect plow components and bolts for wear or damage whenever mounting or removing the plow. Worn or damaged components could permit plow to drop unexpectedly.

\section{WARNING!}

Never put your finger in A-frame ear or coupling lug holes to check alignment. If the plow should move, your finger can be crushed.

32. If the release rod has been misplaced or lost, another one can be fashioned by welding a 3/8-inch bolt that is 1 inch long to a piece of rod or to 3/4-inch rebar material. The handle should be approximately 24 inches long. 


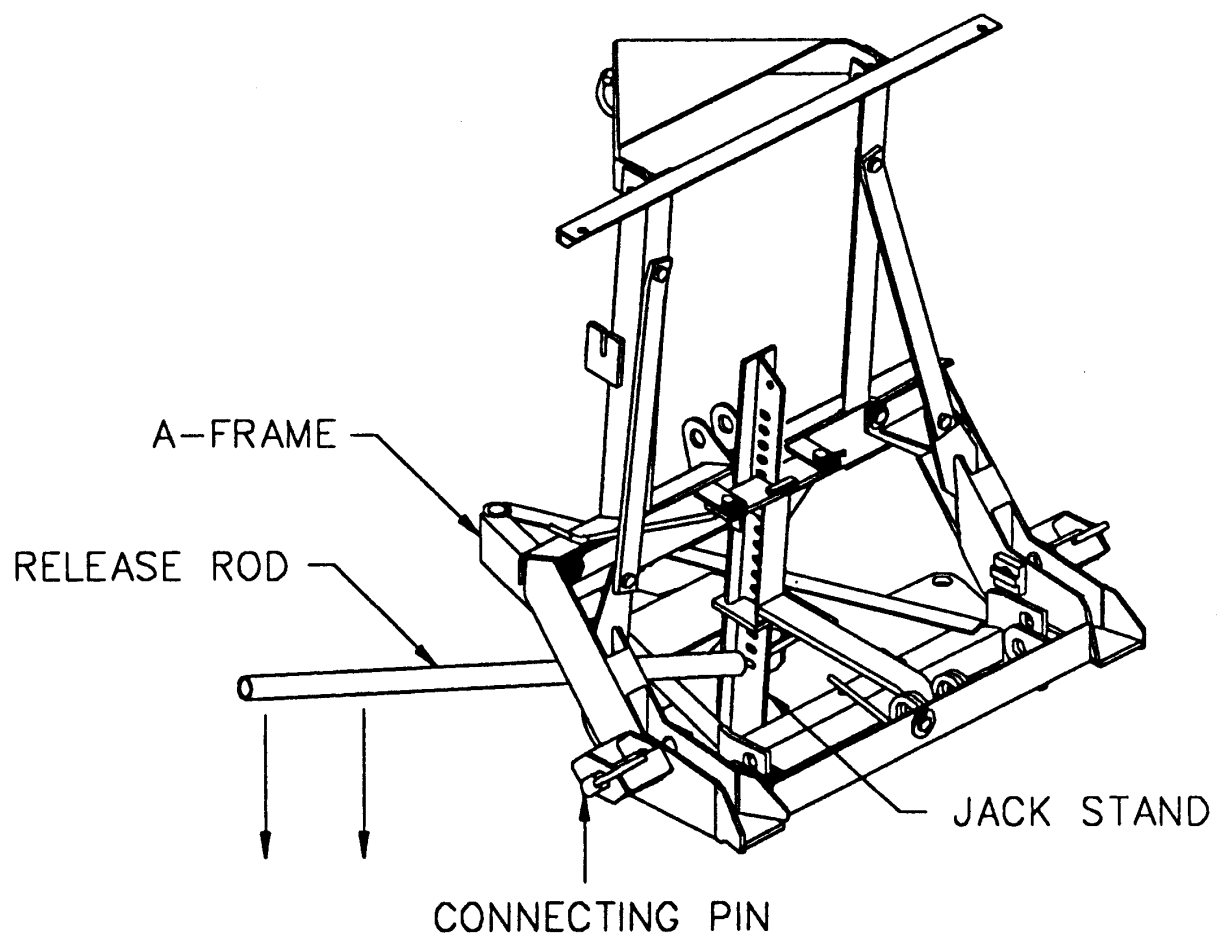

Figure 12. Release rod.

\section{WARNING!}

Note: Do NOT push release rod all the way down. This will create pressure on the connecting pins. 


\section{THE 5-TON TRUCK SNOWPLOW}

\section{Overview}

For more than 30 years, the U.S. Army has not shown much command interest in snow removal. This has been a general course rather than a specific policy. This has been especially true at established military facilities where Directorates of Public Works (DPWs) are well organized. Many installations have a variety of equipment that is reasonably up to date, is well maintained, and is used effectively to manage snow and ice control (SNIC) throughout the winter season. Some installations have a mixture of equipment that fits the particular requirements for their specific location. Snowplows and spreaders have a reasonably long life of twenty years or more, with the spreaders requiring more maintenance because of the corrosive nature of snow melters.

In the field, as well as at some installations, both domestic and overseas, it must be noted that front-end loaders, bulldozers (including the M9 ACE), and motor graders were not designed for snow removal and they are poor substitutes at best. Commanders in the field are generally opposed to using this equipment for SNIC purposes when such equipment has direct mission obligations.

Given current events in the Balkans since 1995 and recent developments there, including a severe winter storm in Kosovo in 1999, HQ USAREUR has taken a primary interest in supporting deployed units with up-to-date quality SNIC equipment. They have ensured that SNIC equipment needs be identified and provided in adequate numbers to meet requirements. This special interest to ensure training and direct support to ensure operational status has proven to be highly successful.

It may be of interest to some to know that the U.S. Army Cold Regions Research and Engineering Laboratory (USCRREL) did not recommend the purchase of snowplows for the 5-ton truck. However, the 5-ton truck is extremely capable on MSRs and is large enough to easily handle heavy snow. Its problem is small, narrow roads with sharp curves or turns. The U.S. Army Corps of Engineers is, however, the proponent for snowplowing operations within the U.S. Army, and stands ready to offer assistance whenever and wherever needed. 


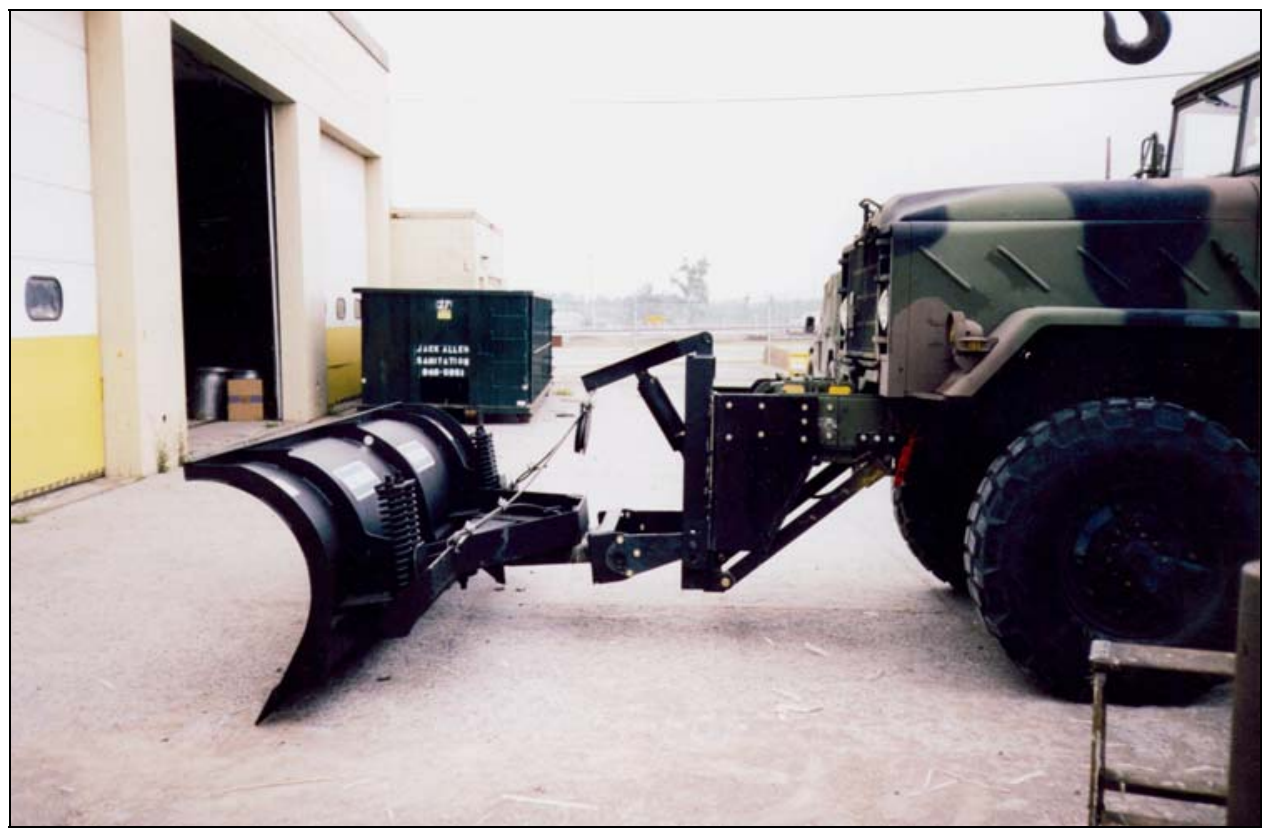

Figure 13. The 5-ton truck snowplow is manually reversible and hydraulically operated, 11 feet wide and 36 inches high. Note the hydraulic ram cylinder as compared to the 1943 jeep shown in Figure 1. The snowplow and its mount puts the snowplow nearly eight feet out in front. Plow guides are a necessity as an aide to the driver.

The 5-ton truck snowplow has been in existence for more than thirty years. It is basic in its design and relative simplicity and is used by many municipalities throughout the country. Its ruggedness and capability have built a highly regarded, long-life reputation. The plow is an excellent piece of equipment.

It was initially tried on the $2-1 / 2$-ton truck, which proved unsatisfactory due to its size, weight, and operational capability. The 5-ton truck is not the vehicle of choice other than on paved MSRs. A 5-ton truck in a $6 \times 6$ configuration does not easily lend itself to use on small roads, service roads, access roads, supply areas, city or town streets, and similar areas where various sharp turns are the rule rather than the exception. The 5-ton truck cannot make a simple right turn from one 16-foot-wide roadway to another 16-foot-wide roadway without having to back up at least twice. This maneuver is extremely hazardous and generally leaves some snow at the intersection. 


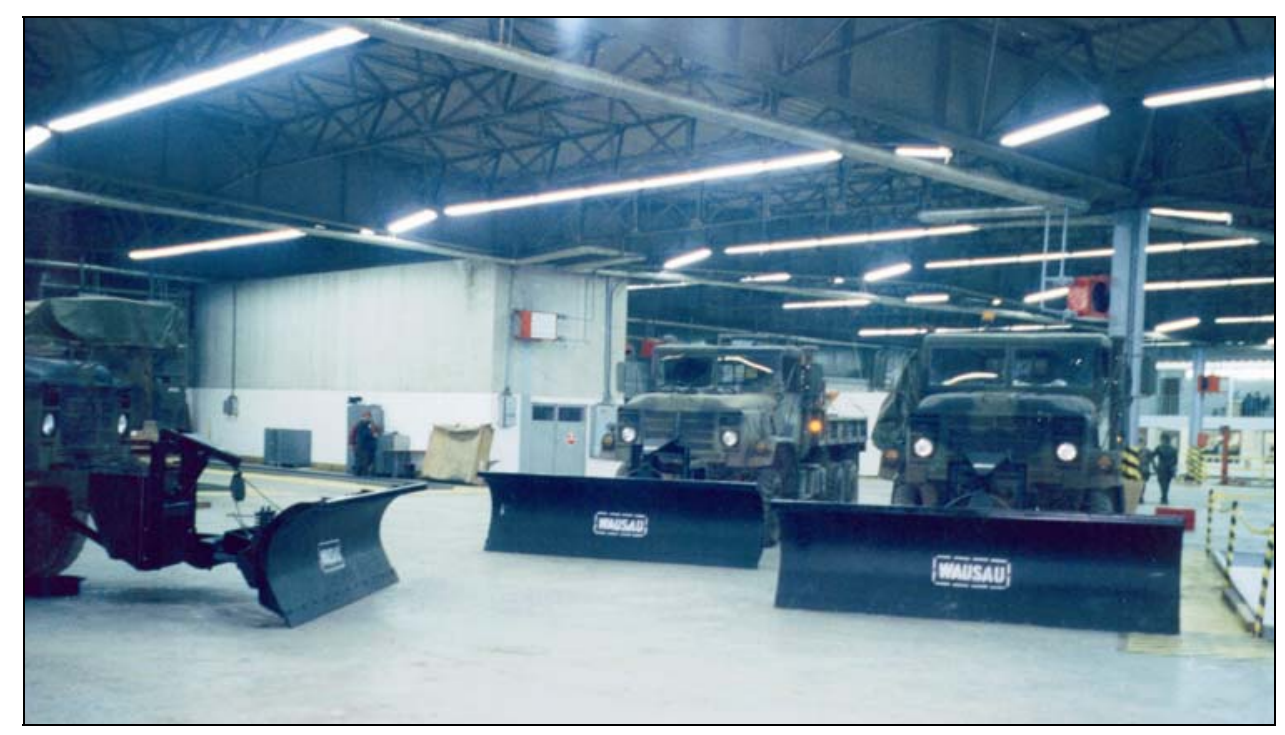

Figure 14. Heavy-duty "Wausau" brand Schmidt snowplows being mounted on 5-ton trucks in Kosovo for use by U.S. Army Kosovo Forces (KFOR). There are five of these plows in Kosovo.

The 5-ton truck snowplow adds 8.2 feet to the front of the truck and requires an experienced driver to be constantly alert when conducting SNIC operations limited to MSRs.

Wausau is a brand name used on particular plows built by the Schmidt Engineering and Equipment, Inc., of New Berlin, Wisconsin. Although basic in design and use, it is very strong and extremely well built. It can effectively and efficiently move large amounts of snow and leaves a clean surface. Although capable of plowing 15 inches or more of new snow, it is strongly recommended that plowing be accomplished during the storm. It is considerably safer, more effective, and more economical to begin plowing before snow accumulation reaches four inches in depth.

During testing and demonstration at Fort Drum, New York, it was found that the 5-ton truck snowplow performs superbly on main roads and does equally well on frozen non-paved roads. When plowing non-paved roads there must be some selectivity on the part of supervisors. In this particular test effort, Fort Drum range roads were being plowed early in the morning after an eight-inch snowfall. There was no traffic on these roads, and in many instances the snowplowing truck would have to go farther than intended to find adequate turn-around space. These range roads did not have sharp curves or steep hills. 


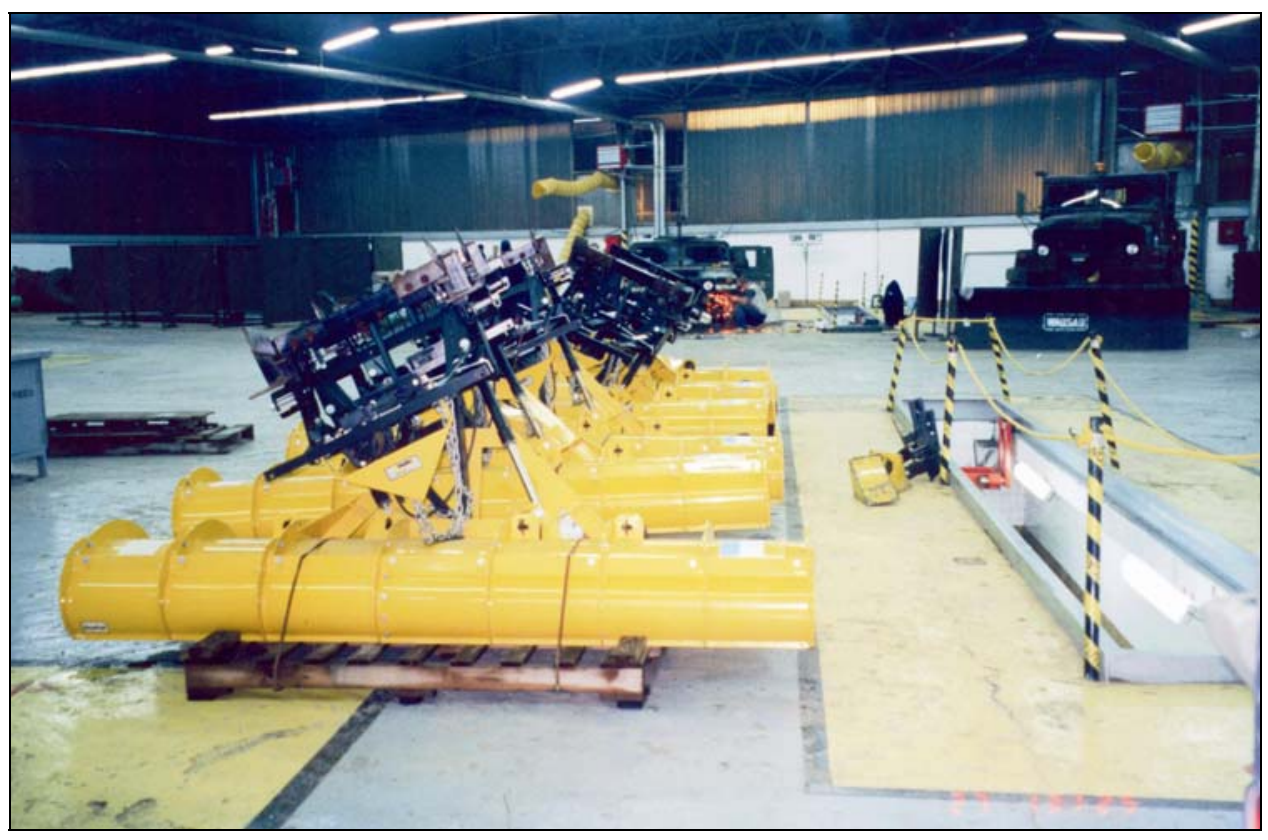

Figure 15. Snowplows in Kosovo ready for installation. Also note 5-ton truck in upper right with snowplow attached.

\section{Operating instructions}

1. In any SNIC operation, it is highly recommended that snowplowing vehicles plow with the storm. If the road being plowed has continuous traffic, then plowing where there is no more than 3-4 inches of snow is considered necessary. With proper plowing and applications of salt, buildup on the road surface can be prevented under most conditions.

2. On loose gravel roads, the 5-ton-truck snowplow needs skid shoes mounted to the plow. This keeps the plow from digging into gravel surfaces. The square shoe was found to be more effective than the round mushroom-type shoe. If shoes are used on the snowplow on primarily paved surfaces, they must be installed correctly and at the same level as the cutting edge of the plow. While testing and demonstrating the 5-ton-truck snowplow, it was comparatively easy to plow new snow from six inches to eight inches, and it proved equally as easy to plow old snow that was three days old although it was obvious that it took more power and in some instances required a second pass to get a clean, smooth surface.

Adding or changing cutting edges is covered in Appendix B. The mounting of the salt/sand spreader is covered in Appendix C. 


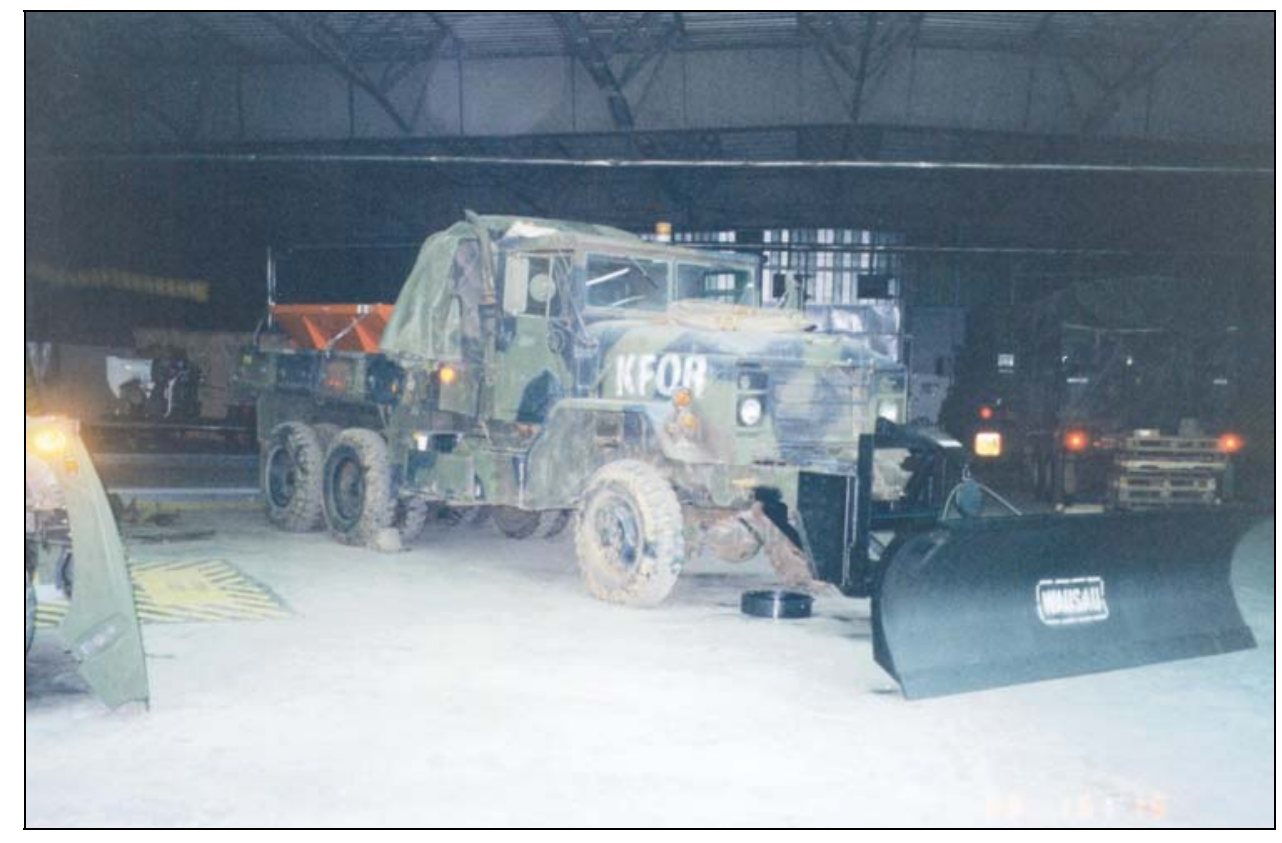

Figure 16. Wausau-brand snowplow manufactured by Schmidt Engineering and Equipment, Inc., of New Berlin, Wisconsin, mounted on a 5-ton truck. The truck has a Henderson "Chief" spreader mounted in the truck bed. Both items can be used simultaneously or separately.

3. The 5-ton truck with snowplow attached is a large piece of equipment and it is recommended that an assistant driver be assigned to the vehicle when it is being used. The assistant driver's primary job would be safety of operations and specifically to watch for possible hazards on the right side of the road. He or she must be especially alert and warn the driver of people or obstructions on the side of the road. The driver must slow down to $5 \mathrm{mph}$ or less and proceed with extreme caution. This plow, Model R3611M, is made of 3/16th high-grade steel for the moldboard and $1 / 2$-inch harder steel in the frame and cutting edge, with a total weight of 1600 pounds. When not used correctly it can cause considerable damage and serious injury.

\section{WARNING!}

Do not operate the plow in the vicinity of suspected hazards or personnel at speeds greater than $4 \mathrm{mph}$. If in doubt, stop and investigate.

Please note: It is never acceptable to plow snow in a manner that will dump the snow or spray the snow on anyone standing or walking along the edge of the road. To take such a risk is both foolhardy and illegal. 


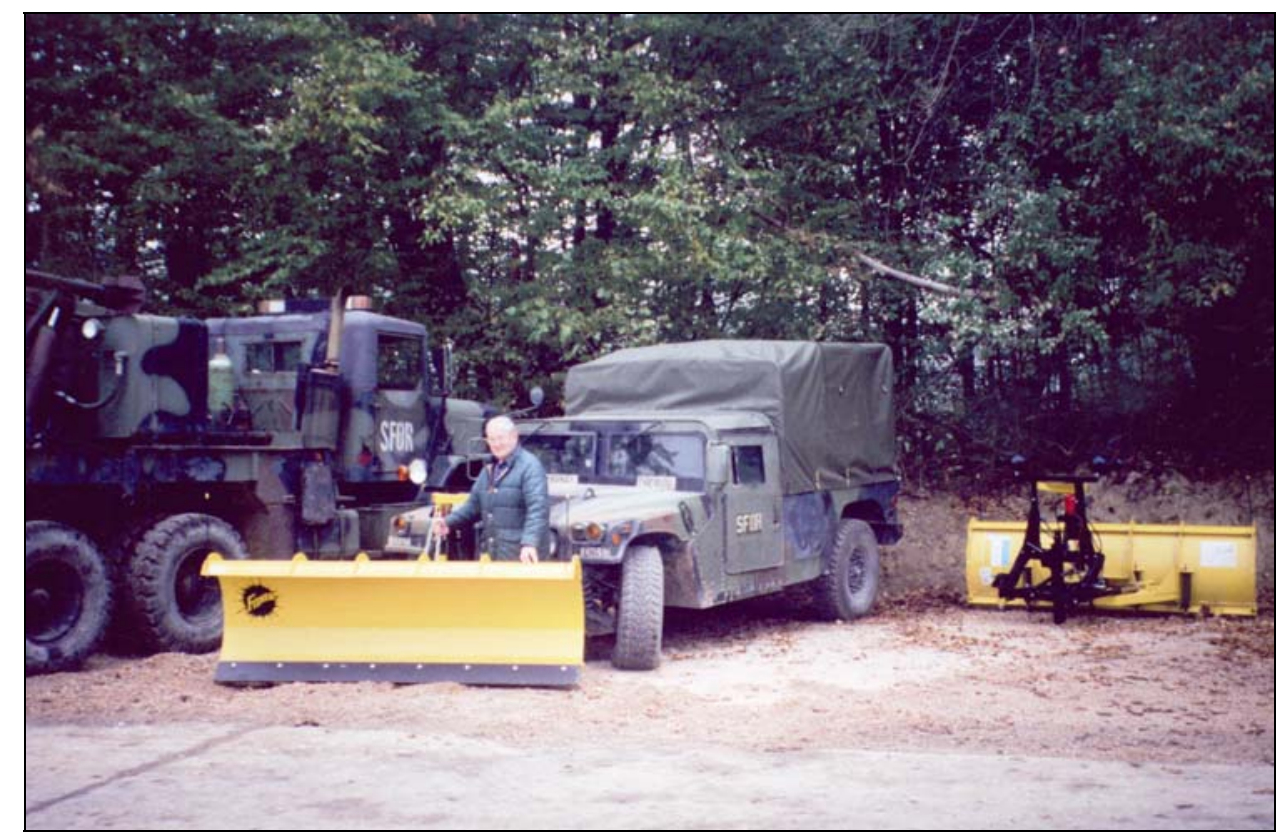

Figure 17. The author inspecting snowplows in Bosnia. These snowplows require their drivers to complete SNIC training.

4. The U.S. Army maximum allowable speed when plowing snow is $10 \mathrm{mph}$. In a ten-hour day, this provides for plowing an average of 100 miles of one lane of a roadway. Slower speeds are always required for suspected obstacles, slower vehicles, bad weather, and other manmade or natural obstructions. The time of day, the terrain, the weather, the surfaces, the driver's experience, and other things must be considered. Though difficult to do, assigning the same drivers to the same sections of roadways to be plowed and salted/sanded greatly enhances the success of the SNIC operations.

5. When making left-hand turns from a two-lane highway onto another roadway, drivers must slow down, watch for oncoming traffic as well as passing traffic, raise the plow before starting the turn, and lower it after crossing the oncoming lane. Normally when plowing snow and having to cross intersections it is hazardous to have to back up and such maneuvers should be avoided if possible. Instead, right-hand turns should be made; however, with the 5-ton truck mounted with snowplow, a lot of room is required and such a turn should not be made until the traffic is clear from the lanes of the right-turn road. A ground guide is required if the driver is forced to back up for any reason. 


\section{WARNING!}

Drivers should not attempt to plow snow with the 5-ton truck on small, narrow roads with sharp curves or steep grades. Supervisors should note this warning and not dispatch the 5-ton truck with snowplow under these hazardous conditions.

\section{5-ton truck support}

1. Installation of or repairs to the 5-ton truck snowplow are accomplished at the depot level OCONUS and by installation repair shops or the manufacturer in CONUS. This snowplow is a non-developmental item (NDI) and a commercial off-the-shelf (COTS) item of equipment. It is a rugged piece of equipment, and seldom needs major repair or parts replacement. In nearly seven years of operation, all repairs have been due to losing parts when dismounting the plow for the summer. See Appendix D for instructions on mounting or dismounting the 5-ton truck snowplow.

2. The U.S. Army does not stock parts for any snowplows, including the plows for the SEE and the HMMWV.

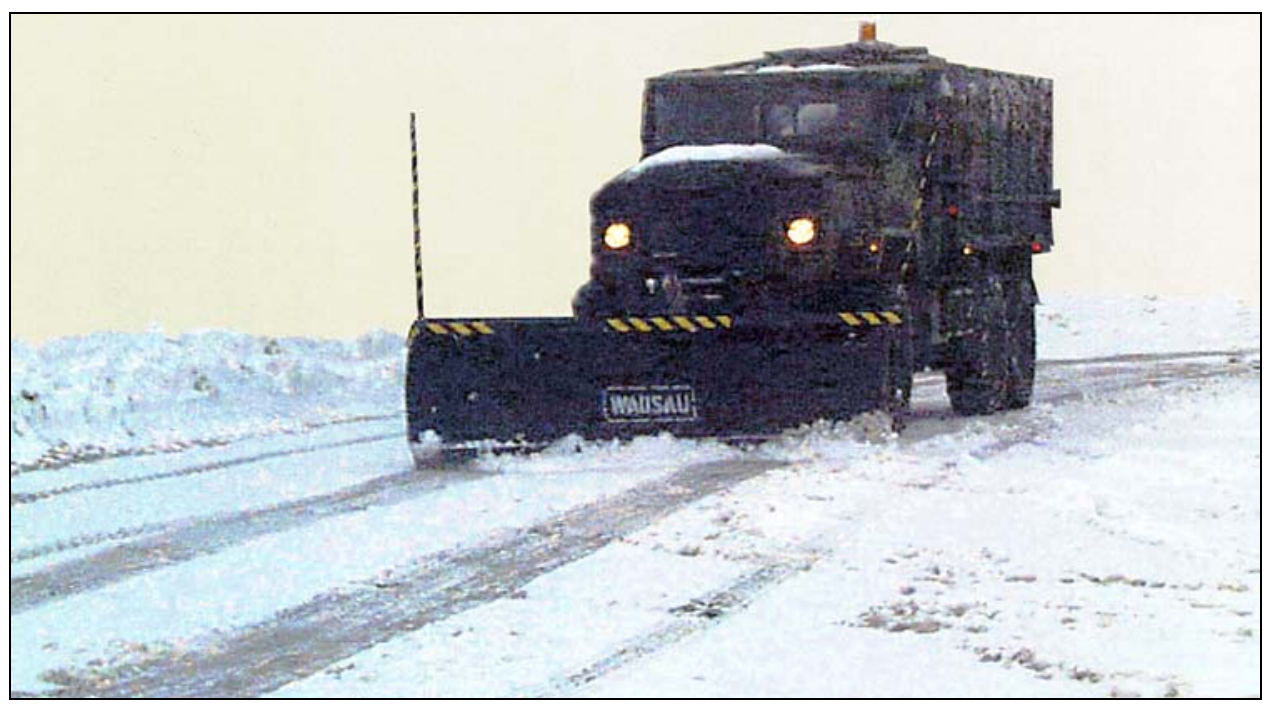

Figure 18. 5-ton truck with snowplow "cleaning up" after a major storm. The use of plow guides is an absolute must for a plow of this size. 


\section{THE SALT/SAND SPREADER}

\section{Overview}

Salt and sand spreaders have been used for more than 60 years. The Henderson Manufacturing Company of Manchester, Iowa, has been making numerous models of salt and sand spreaders for more than 50 years and has produced more than 60,000 spreaders.

The U.S. Army has more than 30 model FS-P spreaders, all of which are in the 6-foot, 8-foot, or 10-foot sizes. The 6-foot spreader has a maximum capacity of 2 cubic yards ( 1.3 cubic yards), the 8-foot spreader has a maximum capacity of 3 cubic yards (1.7 cubic yards), and the 10-foot spreader has a maximum capacity of 3.8 cubic yards ( 2.4 cubic yards). The maximum capacity shown is with 12-inch extensions on the hopper; the figures in parentheses indicate capacity without extensions.

The 6-foot spreader is used on the HMMWV, and the 8-foot and 10-foot spreaders are used on the 5-ton truck. Initially, only the 8-foot spreaders were purchased.

Designed to meet the ice control needs of cities and towns as well as independent operators, the model FS-P is a quick-mounting utility and service spreader, capable of providing fast, efficient service, including spot and cleanup work for bridges, intersections, steep grades, industrial areas, parking lots and staging areas, as well as streets and highways. It has a completely self-contained and self-powered $8.5 \mathrm{hp}$, 4-cycle air-cooled engine that is controlled from the cab. The material being spread is metered for accuracy and economy of spread.

The material is spread by a 12 -inch-diameter spinner fed by a 14-inch-wide chain conveyor. The 4-inch $\times 8$-inch 12-gauge feedgate is lever-operated with side-mounted rules for accurate spreading control. It is recommended that sand or salt be spread with the gate opened one inch with the vehicle speed not to exceed $12 \mathrm{mph}$. If conducting snowplowing operations at the same time, vehicle speed cannot exceed $10 \mathrm{mph}$. This will apply approximately 100 pounds of salt per lane mile (100 lb/ln-mi).

The 14-inch-wide, all steel, riveted pintle chain conveyor belt has $1 / 4-\times 3 / 4$ inch crossbars spaced five inches apart. Chain tensile strength is 11,000 pounds per strand. The top grate screen is a one-piece metal screen with an angle iron frame. This grate must be in place at all times because it keeps larger, unwanted material out of the hopper. Sand and/or salt put through the grate will easily pass 
through the gate unless it is frozen. If salt is left in the hopper for any period of time, it will absorb moisture and become harder than a rock.

Material is guided from the conveyer belt to the spinner through an enclosed chute with two slide-rod adjustable internal deflectors. There are four rod and clip-pin adjustable external deflectors that completely control the material to be spread. Spread width is from four feet to 32 feet.

The engine is an 8.5 horsepower, 4-cycle, air-cooled internal combustion engine that must be operated at maximum speed (3000 to $3600 \mathrm{rpm}$ ) to ensure adequate lubrication, which is provided via the splash system.

Standard equipment includes a 12-volt electric starter and alternator, and an electric clutch that is rated at $90 \mathrm{ft} / \mathrm{lb}$ and which may be engaged or disengaged at any selected engine RPM.

Cab control includes a completely enclosed console with an ignition "On/Off" switch, a push-button starter, and an electric clutch with "On/Off" switch and indicator light. The premium cab control is no longer provided because of heavy abuse and lack of proper care. Repair costs in 2000 averaged $\$ 300$ each for 10 out of 12 of these units. The non-premium units have just the “On/Off” switch, starter, and "On/Off” clutch switch.

Other equipment with the spreader includes a hold-down kit including chains with hooks and binders; the top grate screen, and the inverted vee, which reduces down pressure on the conveyor and helps prevent material compaction.

Every ice control spreader is shipped with a maintenance manual, which includes warranty information as well as installation, maintenance, and safety information. The average life of such manuals in Europe is one day to three months. The manuals mysteriously disappear because of a disease known as "don't-care-itis." Operations manuals suffer the same fate.

\section{Operating instructions}

1. When moving, especially when fully loaded, the vehicle with spreader has a high center of gravity. To avoid overturning the vehicle, you must slow down. Do not exceed five mph when turning or driving on a banked surface. Avoid driving on side slopes. Avoid sharp turns on steep inclines.

2. If a central tire inflation system (CTIS) is available, use it with the crosscountry setting or setting Number 2. If conditions are severe, use the emergency setting. For the SEE Tractor and the HMMWV, use the lowest tire pressure allowed in the operator's handbook. 
3. Be aware that slower is always better than faster; not only is it safer, but the sanding pattern is more effective. The maximum effective speed when sanding is $15 \mathrm{mph}$; however, the ideal speed is $12 \mathrm{mph}$ or less. If plowing snow at the same time, the maximum allowable speed is $10 \mathrm{mph}$.

4. Be constantly alert to the area being sanded and the possibility that an insufficient amount of sand is being spread over the desired area. More sand may be necessary on steep inclines and at intersections. This can be accomplished by slowing vehicle speed to 6-7 $\mathrm{mph}$.

5. Be alert to all conditions and adjust sanding operations accordingly. Limited visibility, severe road conditions, and difficult road surfaces require a slower speed for sanding operations. When in doubt, go slower. Be aware that spreader operations at speeds greater than 10-12 mph may not be appropriate for conditions.

6. Ensure that all persons are clear from the vehicle with sand spreader and when conducting sanding operations. If in doubt, stop and check the area and ascertain that the area is safe for sanding operations.

7. Try to keep the sand as dry as possible. However, if it is damp and is put into the hopper that has the grate installed, and the sand goes through the grate, it will spread sufficiently.

8. Shut off all power before allowing anyone to work on the spreader.

9. Do not conduct sanding operations on a side hill and do not attempt sharp turns on an incline. The possibility of tipping over is very great. Do not mount a spreader in a trailer.

10. Anyone who installs, mounts, or services spreading equipment must be properly instructed and provided with applicable warnings.

11. Follow and adhere to all decal instructions, cautions, and warnings. 


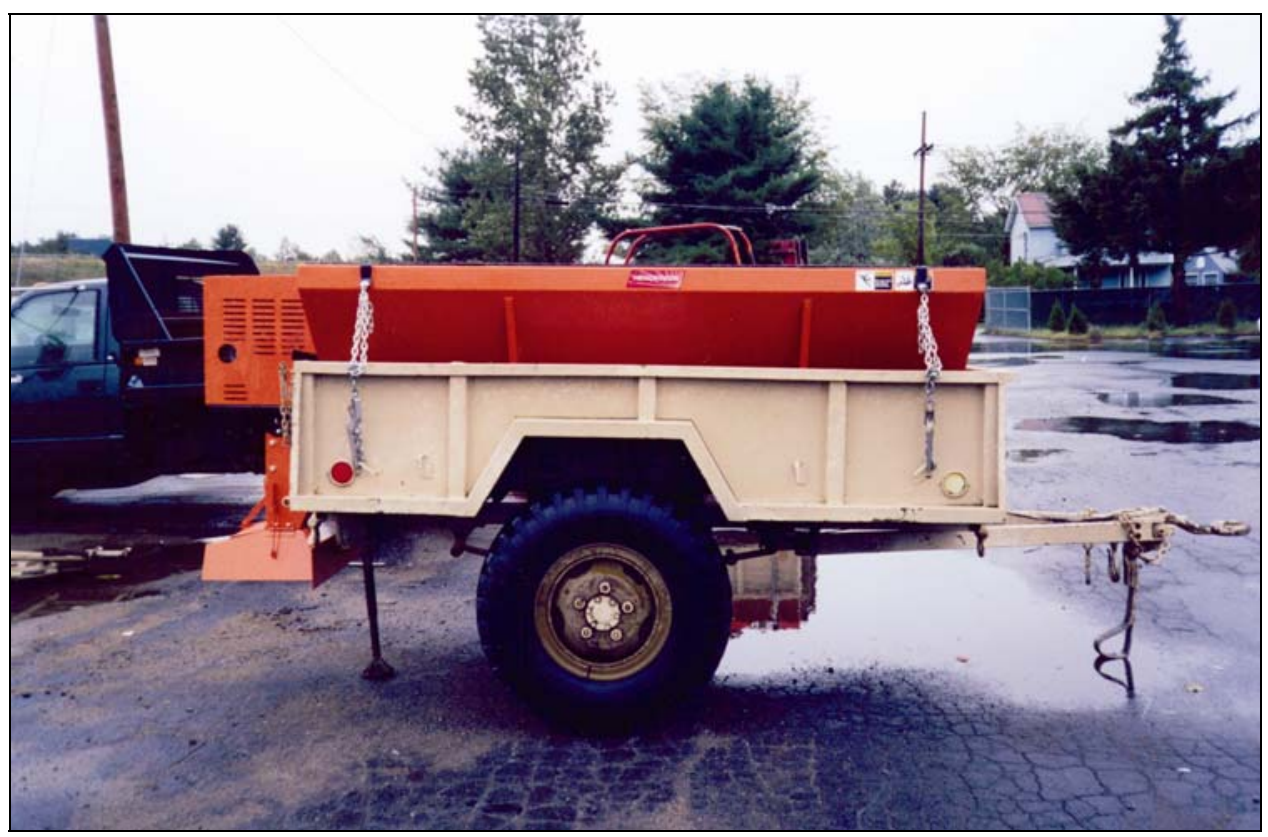

Figure 19. The 6-foot Henderson spreader was mounted on the M100 trailer at the request of commanders in Kosovo. Efforts were made to try to discourage this arrangement because of safety issues. However, the unit insisted, and four of these were made up and shipped. All four suffered accidents-one turned over and took the HMMVW with it. Spreaders should never be mounted in trailers.

12. Check the spreader before performing any operations to ensure that all shields and grates are properly installed.

13. The drive shafts, conveyor (belt), and spinner assemblies transmit considerable amounts of power and are extremely hazardous when operating. Perform all maintenance, inspections, and operator adjustments with the power off.

14. When operating the vehicle with the spreader, keep clear of personnel, equipment, and property. Be considerate of people standing along the edge of the road.

15. Use tire chains at all times when conducting sanding operations on icy roads. Chains enhance vehicle control and provide an added measure of safety. This is especially true on roads with grades and curves.

16. Do not leave spreader running while unattended. Completely disengage spreader, stop engine, shut down truck engine, and secure vehicle. 
17. The conveyor and spinner are controlled by the switch on the cabmounted control panel. The engine may be run continuously or started as needed by the operator using the same control panel.

Note: For proper internal engine lubrication, always operate the spreader engine at full throttle (between 3400 and 3600 RPM). DO NOT idle the engine for extended periods of time. (Engine speed is controlled by the standard throttle cable or the optional electrical throttle control on the cab-mounted control panel.)

18. The higher the feedgate is positioned ( 4 inches maximum), the greater the amount of sand, salt, or sand-salt mixture will be deposited on the spinner. The feedgate is controlled manually from the rear of the spreader.

19. Some rules of thumb for feedgate settings:

a) For absolutely dry sand, a gate opening of $1 / 2$-inch or less is adequate.

b) For normal damp sand, or sand that has 10 percent salt, the gate can be opened 1 to 2 inches. Using the standard opening of $11 / 2$ inches is a common practice for damp or wet sand.

c) For dry salt alone, $1 / 2$ to 1 inch is usually adequate.

d) Salt alone will go farther than sand alone. Mixtures of salt and sand are not generally recommended because they are difficult to mix effectively.

e) A 10-percent mixture may help to prevent damp sand from freezing. However, sand that goes through the grate/screen generally will go through the gate and spread adequately.

20. Adjustable external and internal deflectors for complete control of direction of the spread pattern are on each unit. The width of the spread pattern can be from 4 feet to 32 feet.

21. The recommended speed for sanding operations is 10 to $15 \mathrm{mph}$. Never exceed $20 \mathrm{mph}$. The slower the ground speed, the more sand, salt, or sand-salt can be applied; checking the gate opening to reduce waste is important.

22. Prior to any spreader operations, check the spreader and the spreader engine to ensure good working order. Do not overfill the spreader engine with oil. Measure the oil accurately.

a) Look for damaged or missing parts and repair or replace as necessary.

b) Retighten loose set screws and cap screws, as necessary. 
c) The idler shaft is adjustable for proper chain tensions; tighten the chain until there is no buckling and pintle chain lies flat. (Over-tightening causes excessive wear on bearings and sprockets.)

23. Regular cleaning will prolong the life of the spreader. Empty and clean the spreader unit, including the hopper, conveyor belt, spinner, and all associated parts after each day's use. High-pressure water or steam are effective cleaning agents. Park the unit with the discharge end lower than the front end and block up the conveyor chain to ensure that all salt/sand particles are washed away. Thoroughly clean the rear-end assembly, as accumulations here can affect the spread pattern. Also, take special care when cleaning the floor area, because any buildup here can cause damage to the conveying system. Lubricate/grease all spreader moving parts after washing.

24. If the spreader unit remains on a vehicle or is placed on supports on the ground, ensure that the rear end is lower than the front end for drainage.

25. If the spreader is to be stored for any length of time, take the following actions:

a) Clean the spreader unit completely.

b) Lubricate the unit thoroughly.

c) Repair or replace parts as necessary.

d) Sand, clean, and repaint rusty areas.

e) Store the unit with rear end low for drainage.

26. Control panel operating instructions:

a) Make sure everyone is clear of all moving parts before attempting to start unit.

b) Turn clutch switch to "Off"position. (Engine will not turn over with clutch in "On"position.)

c) The electric throttle control is the upper left-hand switch with "+" INCREASE and "-" DECREASE. By holding switch toward "+" INCREASE for approximately 5 seconds, the control will move from idle to full throttle and stop in the choke position, allowing switch to be released.

d) Turn "ignition" switch to "On"position and push starter button momentarily until engine starts. (Engine RPM reading will come on and show on the console on some models. Otherwise, get out of the vehicle and check to see that the engine is running wide open.) 
e) You will need to "-" DECREASE throttle switch slightly to release engine from choke position.

Note: Look at engine RPM reading when possible to see that you have achieved full throttle settings (3400 to 3600 RPM).

\section{WARNING!}

Engine lubrication is a splash type. Engine should be run at full throttle for longer life. Do not run for more than 2-3 minutes at slower speed.

f) You are now ready to spread. Turn the clutch switch to "On"position and material will instantly be supplied for spreading. Turn to "Off"position and spreading will stop but engine will keep running.

g) To turn off engine and spreader, place clutch switch to "Off" position, throttle down, and turn ignition switch off.

h) Mode button on the console provides the following features. By pushing mode button in and releasing quickly, you can advance to three different functions of console. Note: This feature is not on consoles provided after 2000.

(1) RPM: Engine RPMs

(2) Job Time: Hours and minutes for reading time on current job. To reset hours to " 0 " for next job, hold mode button in for seven seconds under job time setting.

(3) TOT Time: Total Engine Operating Time. This mode is helpful to set up a maintenance program, based on total engine hours and minutes. Total time cannot be reset.

27. Spreader lubrication instructions

a. Proper lubrication is a prime factor in the performance and life of a spreader. Exercise special care in the selection of lubricants and keep them free of foreign matter. Lube applicators should be clean and all fittings, caps, and plugs should be cleaned before lubrication or before opening for any reason.

b. Bearings: Grease all bearings periodically. Relubricate bearings daily or at regular intervals to ensure grease is available to bearings. Grease should be pumped in slowly until a slight bead shows up around the seals. A grease with a high-temperature melting point, above $250^{\circ} \mathrm{F}$, and a low cold test of $-30^{\circ} \mathrm{F}$ is recommended.

c. Conveyor gearcase: Check oil level by removing oil level plug. If low, remove filler plug and add oil only until it runs out of the level hole. Do not 
fill above plug hole. The following lubricants are recommended for use in the conveyor gearcase.

Summer (above $40^{\circ} \mathrm{F}$ ): SAE \#140

Winter (below $40^{\circ} \mathrm{F}$ ): SAE $\# 90$

d. Conveyor chain: Lubricate the conveyor chain frequently. When using chemicals, lubricate the chain daily to ensure clean, smooth running.

e. For other lubrication and schedules consult the spreader manual.

Table 1. Spreader application rate chart.

This is an estimated rate chart based on an engine speed of 3400-3600 rpm and a 1inch gate setting.

\begin{tabular}{|c|c|c|c|c|c|}
\hline \multirow[b]{2}{*}{ Type of Material } & \multicolumn{5}{|c|}{ Vehicle Speed } \\
\hline & $5 \mathrm{mph}$ & $10 \mathrm{mph}$ & $15 \mathrm{mph}$ & $20 \mathrm{mph}$ & $25 \mathrm{mph}$ \\
\hline Sand (Ib per mile) & 2496 & 1248 & 832 & 624 & 499 \\
\hline Salt (Ib per mile) & 1623 & 811 & 541 & 406 & 325 \\
\hline \multicolumn{6}{|c|}{$\begin{array}{l}\text { Calculations based on } 100 \text { pounds/foot }{ }^{3} \text { sand and } 65 \text { pounds/ft }{ }^{3} \text { salt. } \\
\text { Note: Speed and gate opening dramatically affect amount being spread. As a general } \\
\text { rule of thumb, spread sand at a rate of } 625 \mathrm{lb} / \mathrm{In}-\mathrm{mi} \text { and salt at a rate of } 406 \mathrm{Ib} / \mathrm{ln}-\mathrm{mi} \text {. To } \\
\text { do this, set gate opening at } 1 / 2 \text { inch and maintain } 10 \mathrm{mph} \text {. }\end{array}$} \\
\hline
\end{tabular}




\section{APPENDIX A: ANTI-ICING OPERATIONS GUIDE}

\section{Introduction}

This appendix is a guide to highway anti-icing operations for maintenance field personnel. Its purpose is to suggest maintenance actions for preventing the formation or development of packed and bonded snow or bonded ice during a variety of winter weather events. It is intended to complement the decision making and management practices of a systematic anti-icing program so that roads can be efficiently maintained in the best possible condition.

The guidance is based upon the results of four years of anti-icing field testing conducted by fifteen State highway agencies and supported by the Strategic Highway Research Program (SHRP) and the Federal Highway Administration (FHWA). It has been augmented with practices developed outside the United States, where necessary, for completeness. The recommendations are subject to refinement as U.S. highway agencies gain additional experience with anti-icing operations. Final decisions for their implementation rest with management personnel.

\section{Guidance for anti-icing operations}

Guidance for anti-icing operations is presented in the tables that follow for six distinctive winter weather events. The six events are as follows:

- Light snowstorm (Table A1)

- Light snowstorm with period(s) of moderate or heavy snow (Table A2)

- Moderate or heavy snowstorm (Table A3)

- Frost or black ice (Table A4)

- Freezing rain storm (Table A5)

- Sleet storm (Table A6)

The tables suggest the appropriate maintenance action to take during an initial or subsequent (follow-up) anti-icing operation for a given precipitation or icing event. Each action is defined for a range of pavement temperatures and an associated temperature trend. For some events the operation is dependent not only on the pavement temperature and trend, but also upon the pavement surface or the traffic condition at the time of the action. Most of the maintenance actions involve the application of a chemical in either a dry solid, liquid, or pre-wetted solid form. A suggested application rate, or range of rates, is given for each 
chemical form where appropriate. The application rates given for liquid chemicals are the equivalent dry chemical rates.

Comments and notes are given in each table where appropriate to further guide the maintenance field personnel in their anti-icing operations.

\section{Glossary}

Black ice. Popular term for a very thin coating of clear, bubble-free, homogenous ice that forms on a pavement with a temperature at or slightly above $32^{\circ} \mathrm{F}$ when the temperature of the air in contact with the ground is below the freezing point of water and small slightly supercooled water droplets deposit on the surface and coalesce (flow together) before freezing.

Freezing rain. Supercooled droplets of liquid precipitation falling on a surface whose temperature is below or slightly above freezing, resulting in a hard, slick, generally thick coating of ice commonly called glaze or clear ice. Non-supercooled raindrops falling on a surface whose temperature is well below freezing will also result in glaze.

Frost. Also called hoarfrost. Ice crystals in the form of scales, needles, feathers, or fans deposited on surfaces cooled by radiation or by other processes. The deposit may be composed of drops of dew frozen after deposition and of ice formed directly from water vapor at a temperature below $32^{\circ} \mathrm{F}$ (sublimation).

Light snow. Snow falling at the rate of less than half an inch per hour; visibility is not affected adversely.

Liquid chemical. A chemical solution; the weight of the dry chemical in solution applied per lane mile is the chemical application rate used in this guide.

Moderate or heavy snow. Snow falling at a rate of half an inch per hour or greater; visibility may be reduced.

Sleet. A mixture of rain and snow that has been partially melted by falling through an atmosphere with a temperature slightly above freezing.

Slush. Accumulation of snow that lies on an impervious base and is saturated with water in excess of its freely drained capacity. It will not support any weight when stepped or driven on but will "squish" until the base support is reached.

Ib/ln-mi. Pounds per lane mile of roadway. 


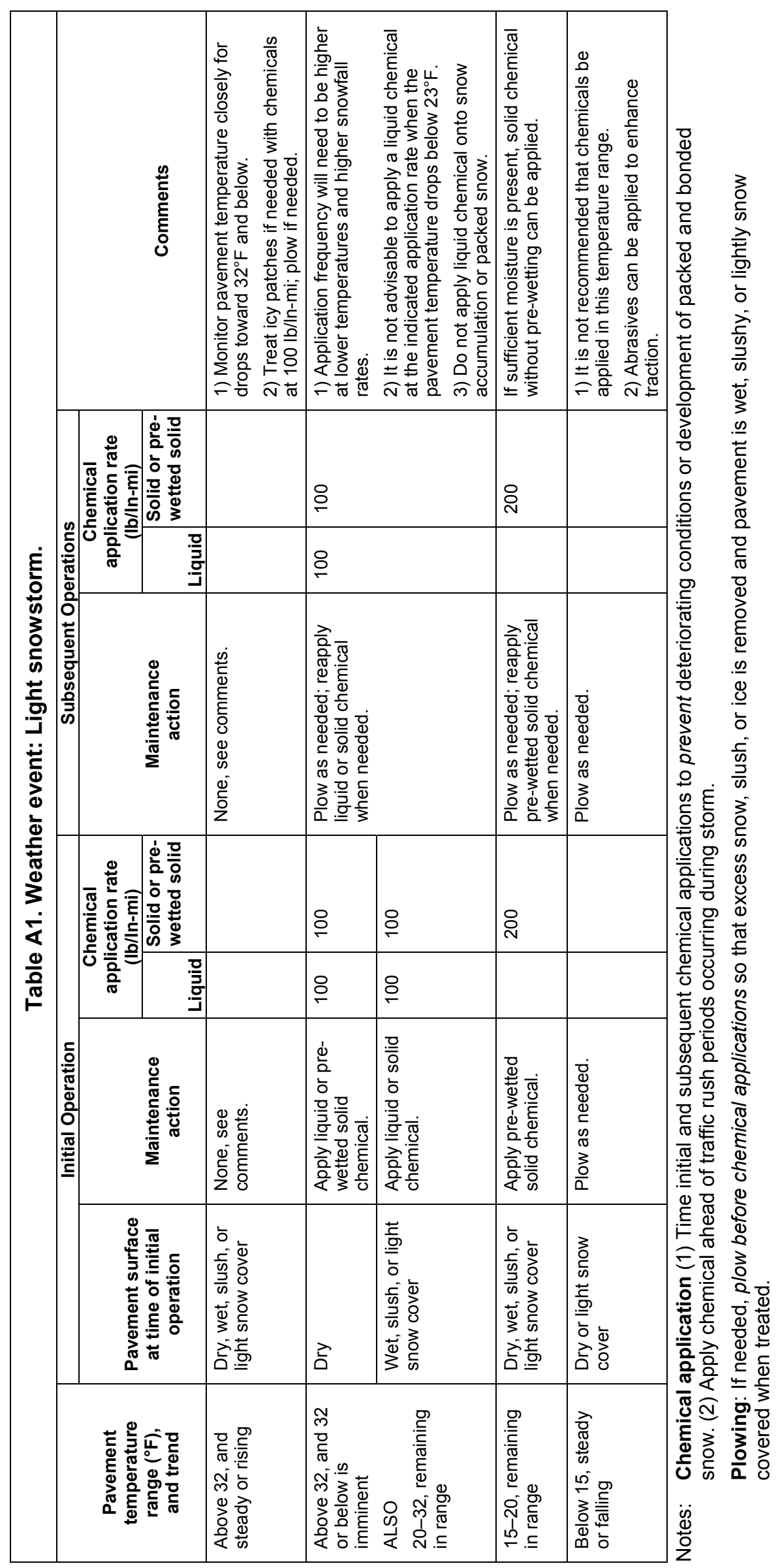




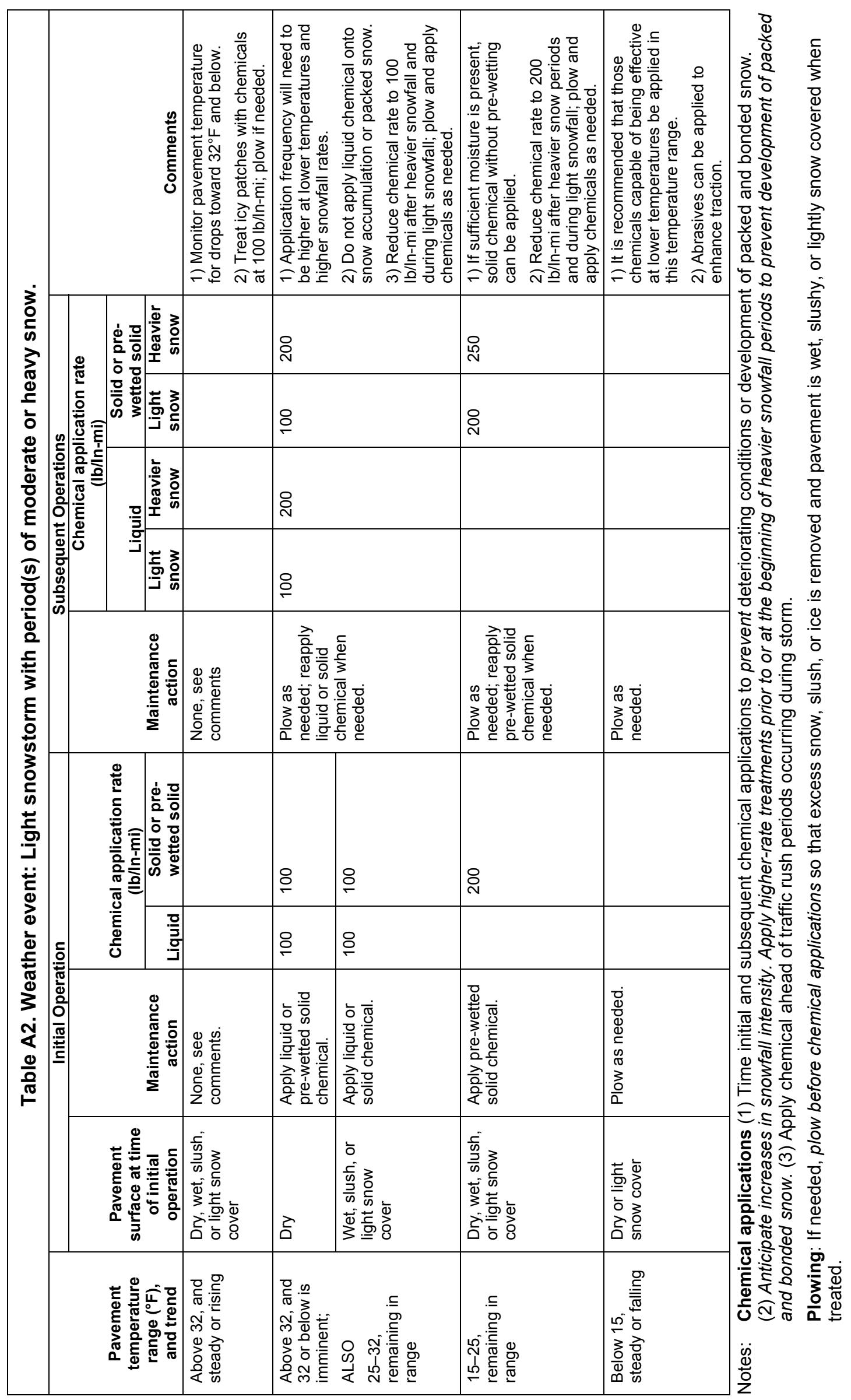




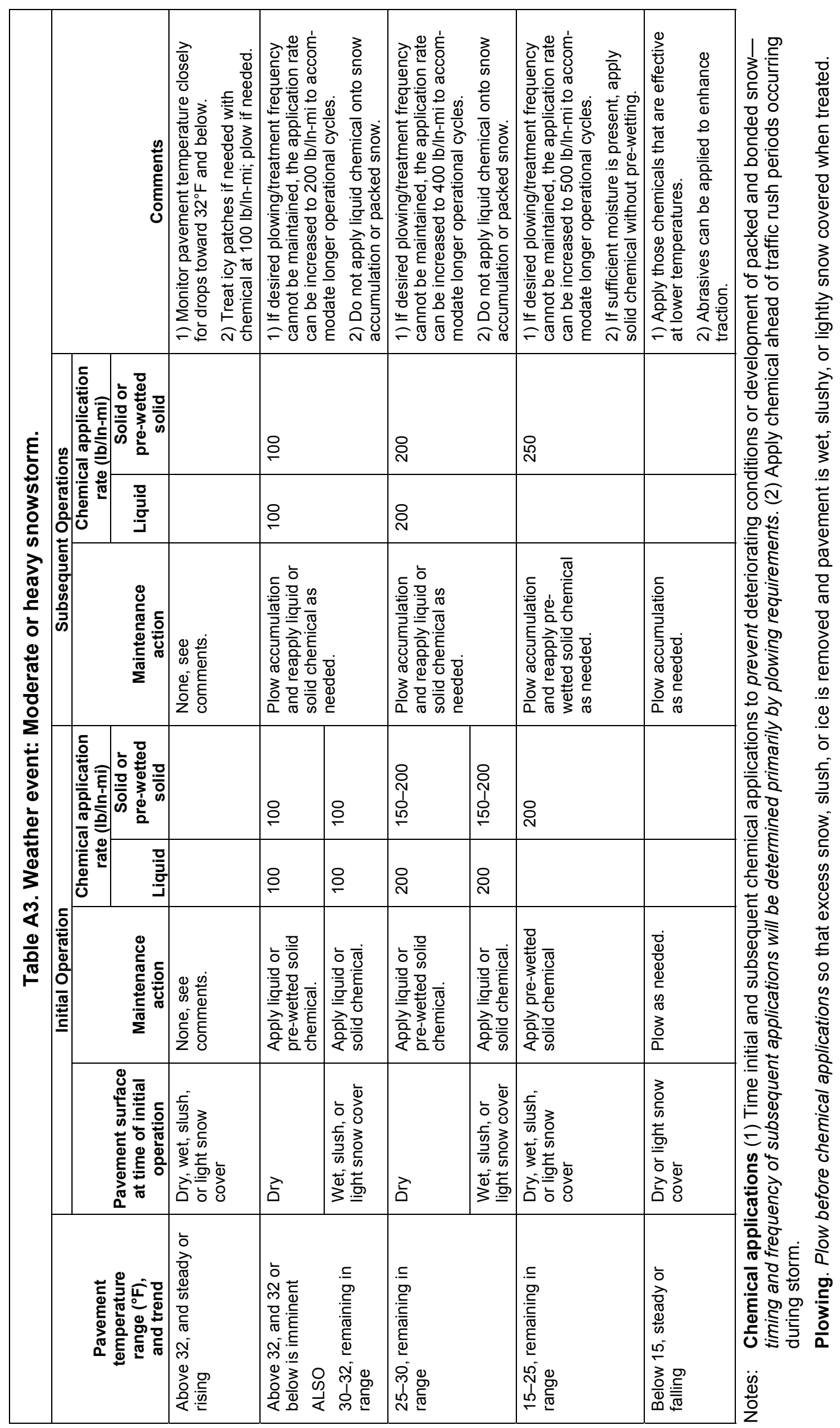




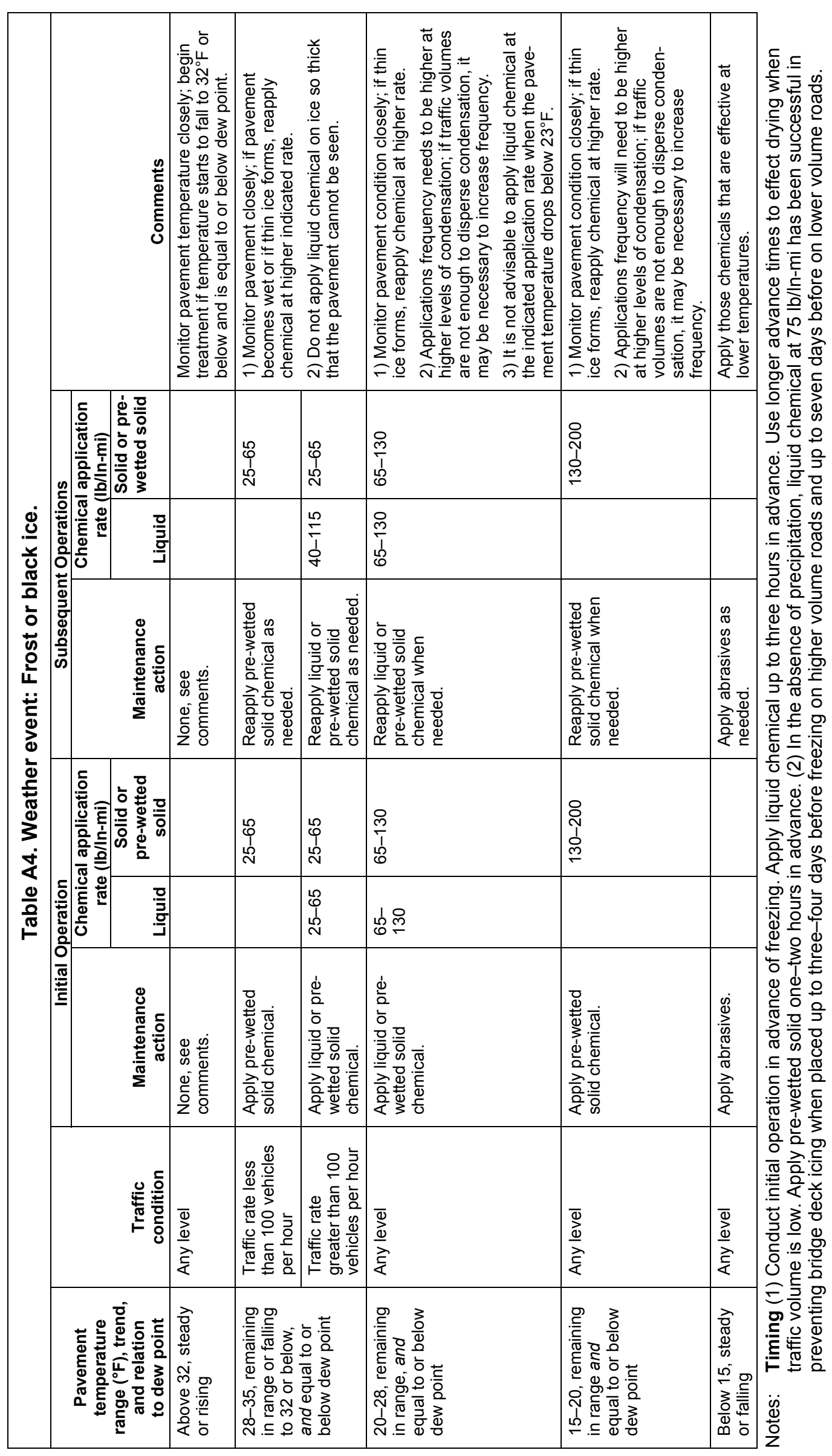




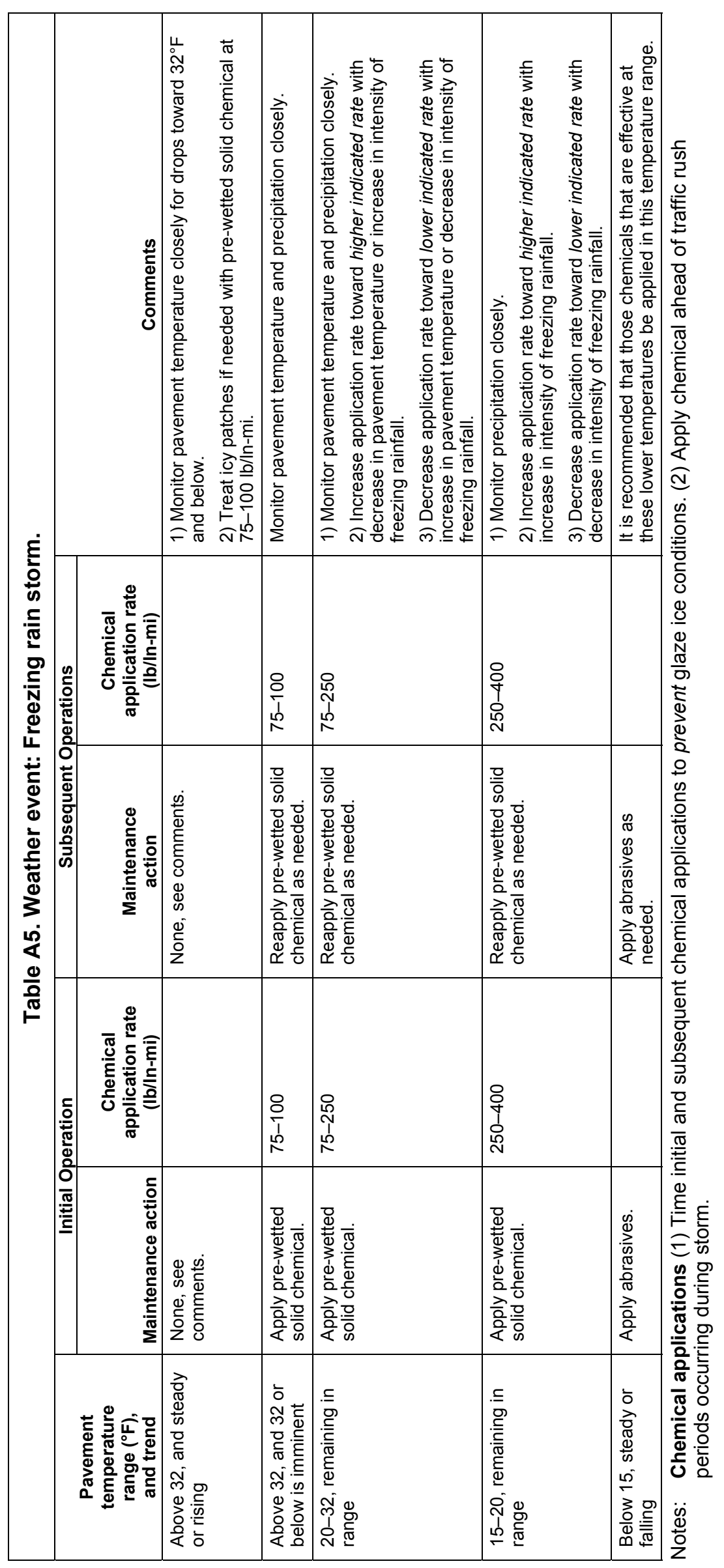




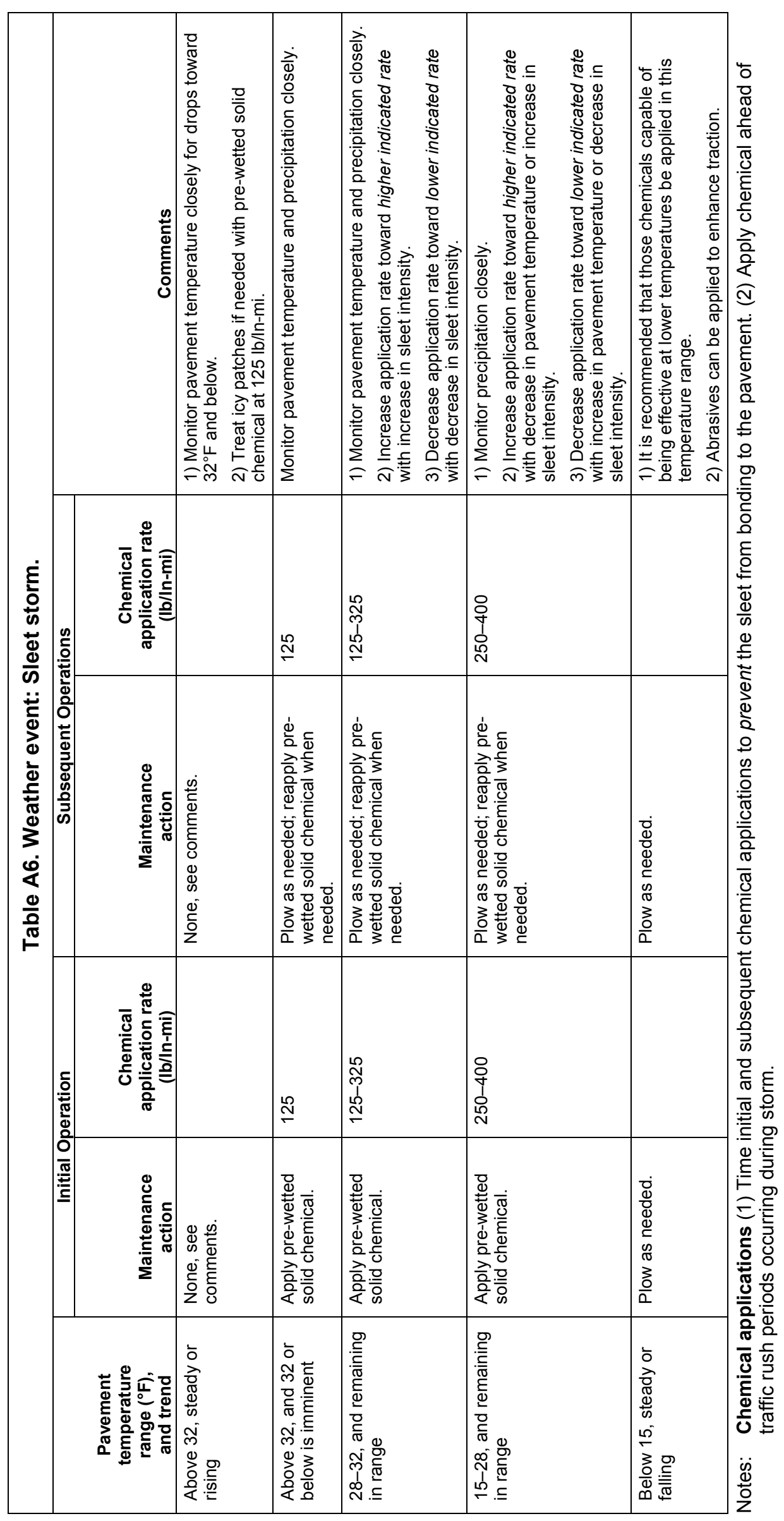




\section{APPENDIX B: CUTTING EDGE INSTALLATION ON THE 5-TON TRUCK SNOWPLOW}

Installing the carbide blades and the steel blade together on the R3611M "Wausau" brand Schmidt Engineering and Equipment, Inc. snowplow requires the following steps:

1. Raise the blade mounted on the truck, and place heavy timbers just under the plow frame immediately behind the plow moldboard. Allow enough room to reach the nuts along the bottom edge and to use an impact wrench. Leave the blade attached to the truck.

2. Be sure the brakes on the truck are set and shut down the engine.

3. Remove the old cutting edge by removing all the bolts along the bottom. Unless some have been lost, there normally are 13 bolts to remove. Clean the area along the bottom of all rust and dirt; a wire brush works well. If you have time, spray all rust areas with rust inhibitor paint.

4. To install the new combination cutting edges, put one of the 4-foot pieces of carbide steel cutting edge on one end. Hold in place by using two recessed-head short bolts installed as indicated by the small arrows. Tighten the nuts loosely to hold the 4-foot piece in place.

5. Then install the other 4-foot piece on the other end. Hold it in place by two recessed-head short bolts and tighten only loosely. Then install the 3-foot piece in the middle, hold in place with one recessed-head short bolt, and tighten only loosely.

6. Finally, install the 11-foot steel blade; put a non-recessed-head long bolt at each end and tighten only loosely; then install the other six long bolts and tighten loosely. Then, using an impact wrench and beginning in the middle, tighten each bolt alternately until all are secure.

7. CAUTION: Blades are heavy and if dropped can cause severe injury to hands and feet. Use two persons at all times and work slowly and carefully. Be sure no one climbs into the truck while this work is being done. 


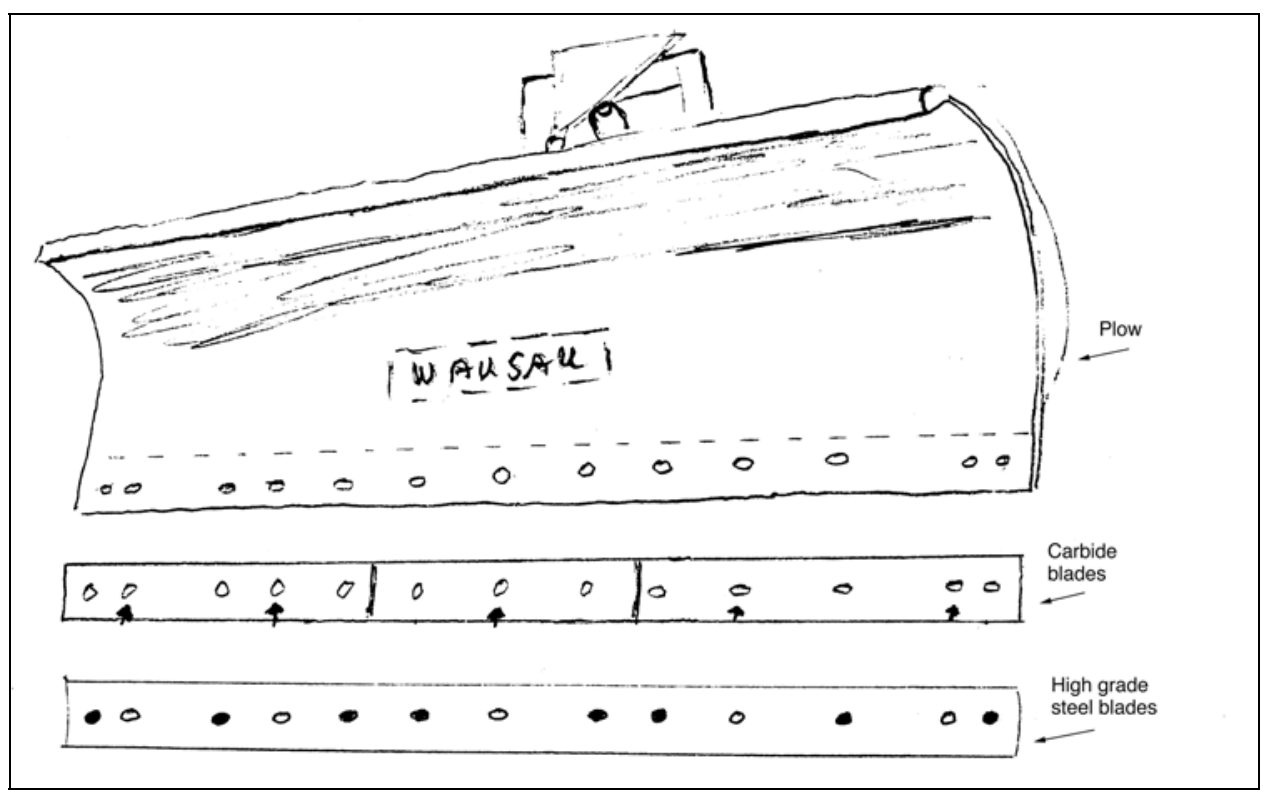

Figure B1. Schmidt Engineering and Equipment, Inc., "Wausau" brand R3611M snowplow. 


\section{APPENDIX C: SPREADER MOUNTING INSTRUCTIONS}

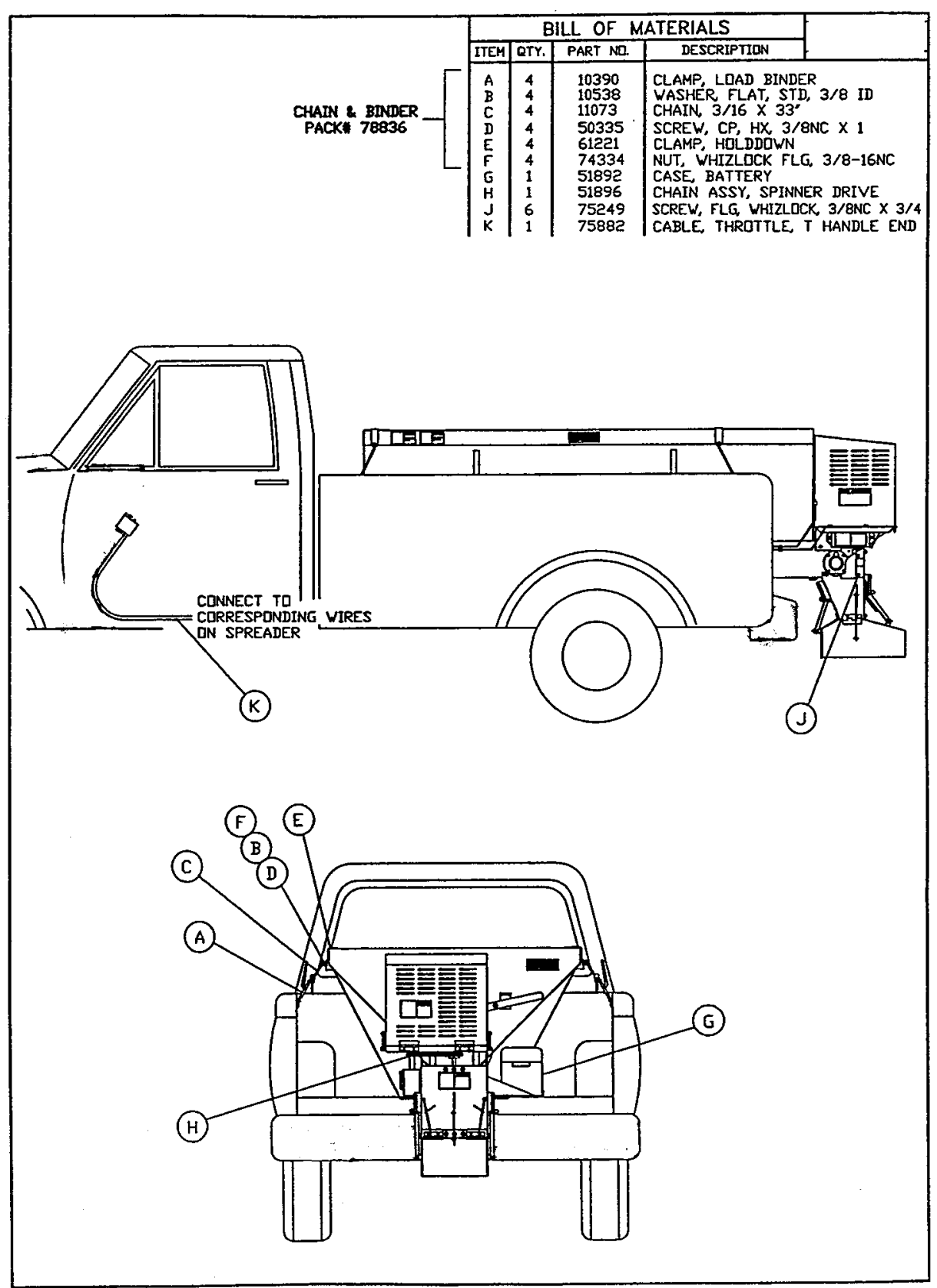




\section{APPENDIX D: WAUSAU REVERSIBLE SNOWPLOW FOR THE 5-TON TRUCK}

\section{Background}

The reversible snowplow is designed to cast snow to either the left- or the right-hand side of the road. The plow also can be used without any angle in the forward position to pile snow out of the way or for easy removal with a snowblower or front loader. This plow is most commonly used in the full right-hand position to clear snow to the right-hand side of the road.

The reversing mechanism of the R-series plow consists of a drive frame (mounted to the truck) and a sector frame, which is mounted to the snowplow. This particular snowplow, the R3611M, has a manually operated reversing mechanism. To reverse the plow from a right-hand plowing mode to a left-hand plowing mode, the plow needs to be leveled and preferably resting on a 2 -inch $\times$ 4-inch piece of lumber. Then remove the pin holding the plow in place on the sector frame and move the plow to the left and re-install the pin. Note: It is recommended that two people should manually reverse the plow, being especially careful to keep hands and feet clear of all moving parts. Keep hands and feet away from the plow cutting edge at all times.

As a safety feature, the $\mathrm{R}$ series plow has four large compression springs mounted in a way that allows the moldboard to rotate forward and slide over obstructions. The force required to compress these springs will bring the plow back to its original plowing position. The driver should stop and investigate the obstruction, determine what it is, and report it. If it is a permanent structure it should be marked so that the plow will not hit it again.

The plow has a cutting edge to scrape snow and most ice off the road surface, and works most efficiently when the cutting edge is on the ground. The cutting edge can be enhanced with a carbide steel cutting edge as shown in Appendix B.

To lift the plow, the truck hitch lifting mechanism is operated with the hydraulic lift cylinder and a lift arm. The winch control in the cab provides this action. Connected to the lift arm is a "dead sheave" arrangement consisting of a sheave and a steel cable. The cable must be wrapped around the sheave once to create enough friction between the cable and the sheave to keep the plow level in the carrying position.

In all cases, to carry the plow level, the reversing of the plow has to be done when the plow is on a sturdy board or a plank on the ground. This is very impor- 
tant because when reversing occurs in the lift position, the plow will list to one side in an unsafe manner.

When plowing or when carrying the plow in a raised position, if the cylinder does not hold the load, the hydraulic relief pressure is set too low and should be increased to the point where the plow will work satisfactorily. For plowing snow, this pressure setting is approximately 2,000 pounds per square inch (psi).

\section{Mounting instructions for the 225B hitch on military truck with winch}

This truck has a hydraulical winch that operates the plow lift and reversing mechanism.

The valve bank has two sections: one section has an open center, and the other has a closed center position. Because the plow needs two valve sections with closed center positions, it will be necessary to replace one section on the valve bank. (See instructions shipped with plow.)

The front of the truck also is supplied with two tow hooks. These two tow hooks must be removed in order to mount the hitch.

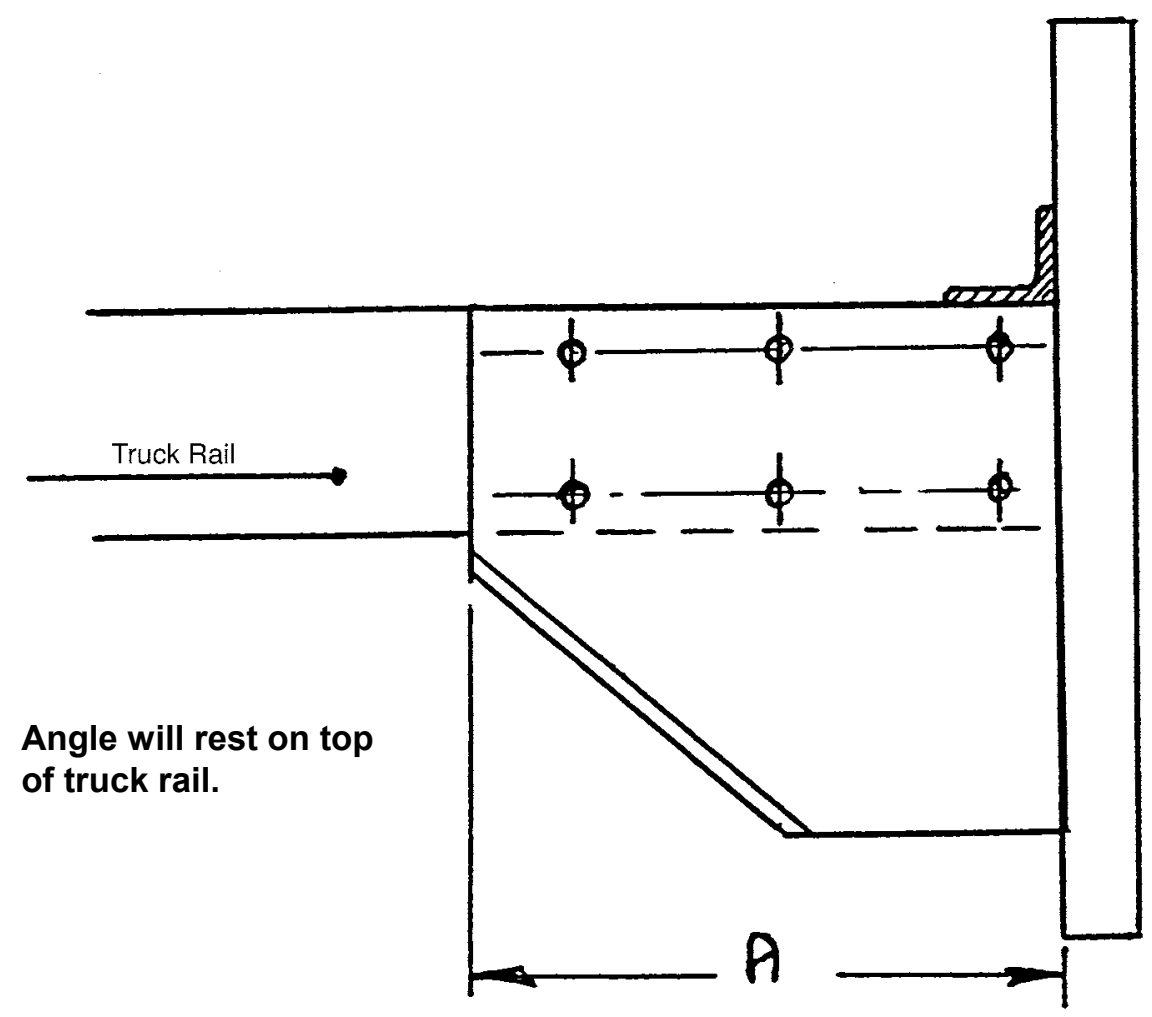


- Mount plow to drive frame.

- Mount end plates to drive frame in such a way that centerline of plates and drive frame are close to being "in-line" with each other.

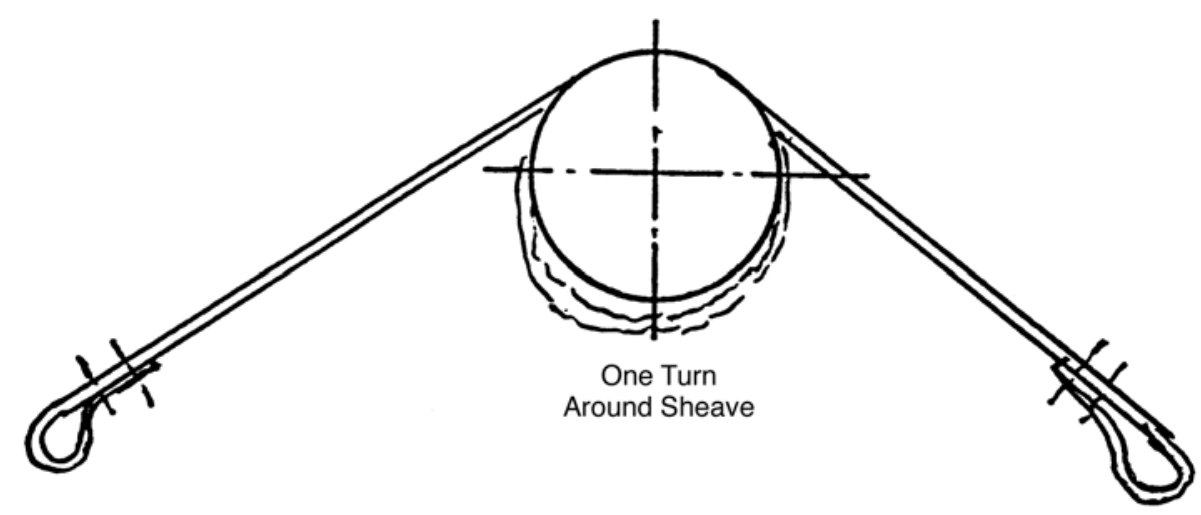

- Make sure distance between end plates will match mounting holes on hitch. If adjustment is needed, flat washers will be placed between end plates and plates on drive frame.

- Slide plow and drive frame into hitch and fasten with drive pins.

- Secure pins with cotter pins.

- Mount hydraulic cylinder to hitch and lift arm and see section on hydraulics to mount valve section and hoses.

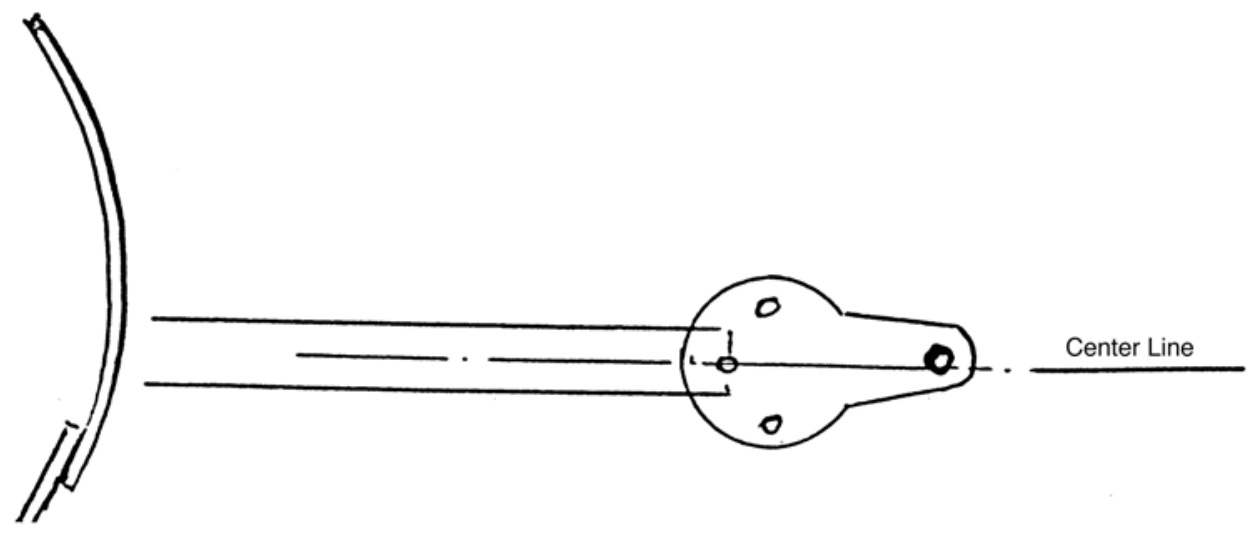

- Remove over a distance " $\mathrm{A}$ " on front truck rail, all bolts and nuts.

- Slide hitch over truck rail until front touches truck rail and top angle is resting on rail. 
- Line up winch mounting holes on front and clamp hitch to truck rail and drill all holes in truck rail. (See diagram on page 57.)

- Drill first $\varnothing 1 / 4$-inch holes and then drill holes according to the size in plow hitch.

- Fasten plow hitch with bolts and lock nuts and remove clamps.

- Mount drive frame to truck.

- Place steel cable through left hole on drive frame and feed cable through approximately 16 inches and fasten with cable clamps.

- Slide cable through sheave (one full turn around sheave) and mount on right-hand side of drive frame. 


\section{APPENDIX E: ORDERING PARTS FOR COMMERCIAL OFF-THE-SHELF (COTS) EQUIPMENT}

1. The following applies to commercial parts for the HMMWV, SEE tractor, and 5-ton truck snowplows, and the Henderson salt/sand spreader, as well as related equipment and parts.

Request delivery by U.S. Mail for all orders from OCONUS. The option known as Priority Mail generally ensures better service and may speed delivery.

You may be able to request "Express Mail," but not all APOs provide this service and therefore the shipping Post Office may not accept this request.

If you want your package to be fully accountable, ship it "Registered MailReturn Receipt Requested.” This service adds approximately $\$ 7.50$ to the usual postage. This is recommended for valuable mail sent to places such as Task Force Eagle. You also can use "Certified Mail—Return Receipt Requested." This will add approximately $\$ 2.70$ to the normal postage.

Individual packages cannot exceed a total weight of 70 pounds. All packages require a customs form.

2. Please note: Units deployed in areas of the Balkans such as Bosnia, Kosovo, and Macedonia are not authorized to make repairs on SNIC equipment. In these areas the Brown and Root Services (BRS) organization is under contract to provide all repairs to U.S. Army SNIC equipment. Units in these areas are restricted to cleaning, lubricating, and replacing headlights and directional light bulbs. BRS should order and provide necessary repair parts.

3. To order parts for the Henderson Spreader, contact

Henderson Manufacturing, Inc.

c/o Parts (Attn: Lou Ann March)

1085 South Third Street

Manchester, Iowa 52057-0040

Telephone number: 563-927-7236

Fax number: 563-927-2521

E-mail: LAMarch@,henderson-mfg.com

Web site: http://www.henderson-mfg.com 
If you are ordering from an APO in Europe and want to save postage and time, you can order common items for the Henderson Spreader from the following dealer:

Bart Truck Equipment Co., Inc.

c/o Parts (Attn: Tom Dentzau or Jim DeClamenti)

358 River Street

West Springfield, Massachusetts 01089

Telephone number: 413-737-2765

Fax number: 413-737-2766

E-mail: Tom@,ATBART.aol.com or Jim@,ATBART.aol.com

4. To order parts for the HMMWV Snowplow:

Arrowhead Equipment, Inc.

Attn: Parts [M. Gebo]

106 Luzerne Road

Queensbury, New York 12804

Telephone number: 518-793-2265

Fax number: (518) 7932597

E-mail: info@arrowheadequipment.com (Gebo)

Web site: http:// www.arrowheadequipment.com

5. To order parts for the SEE Tractor and/or the 5-ton Truck Snowplows:

Schmidt Engineering \& Equipment, Inc.

Attn: Parts ( S. Jesion)

1905 South Moorland Road

New Berlin, Wisconsin 53151

Telephone number: 262-784-6066

Fax number: 262-784-1395

*E-mail: sales@,see-worldwide.com

*Web site: http://www.SEE-worldwide.com

* "SEE" in the Schmidt Engineering e-mail and Web site addresses does not refer to the SEE tractor; it refers to Schmidt Engineering and Equipment, Inc. 


\section{APPENDIX F: HMMWV 8-FT SNOWPLOW WITH INTEGRAL ATTACHMENTS}
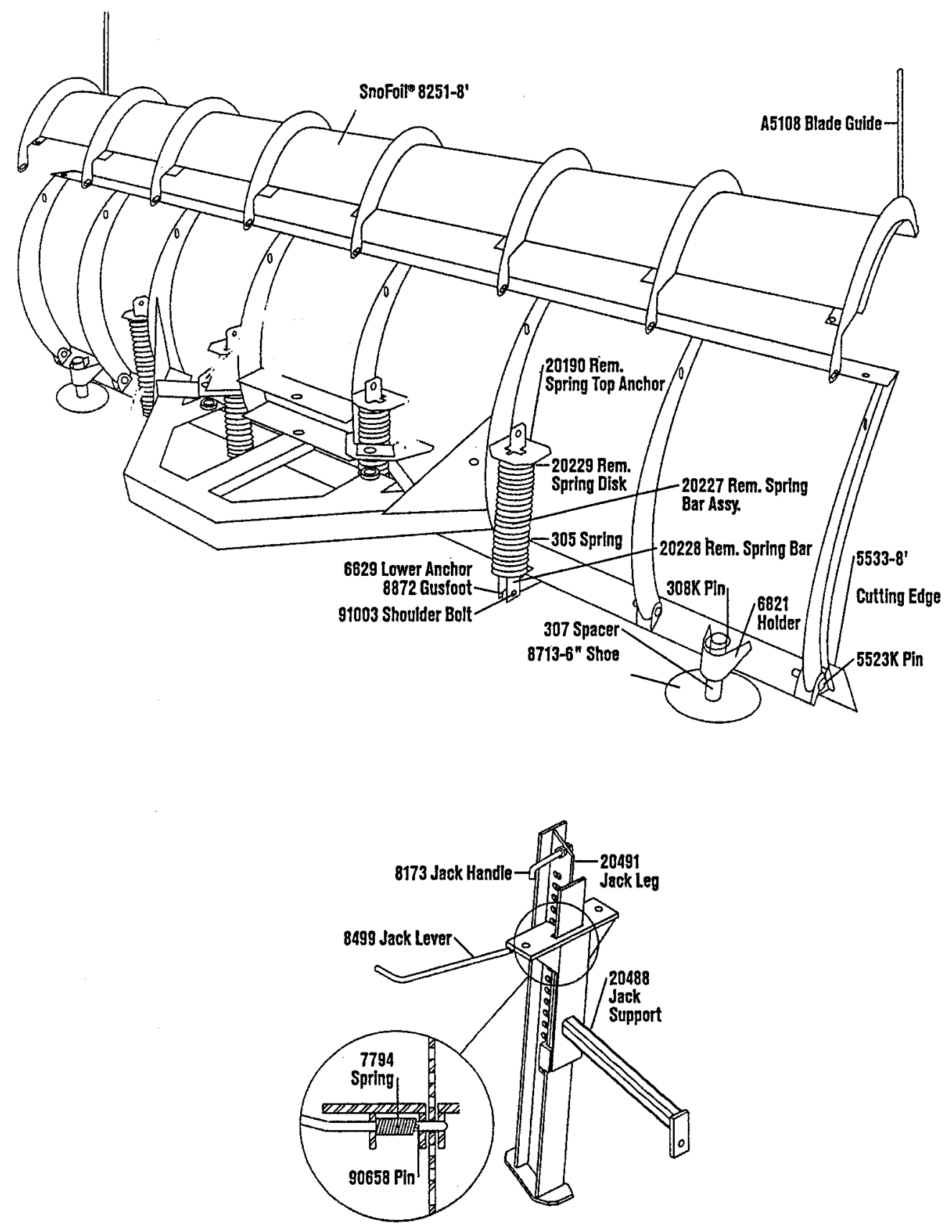


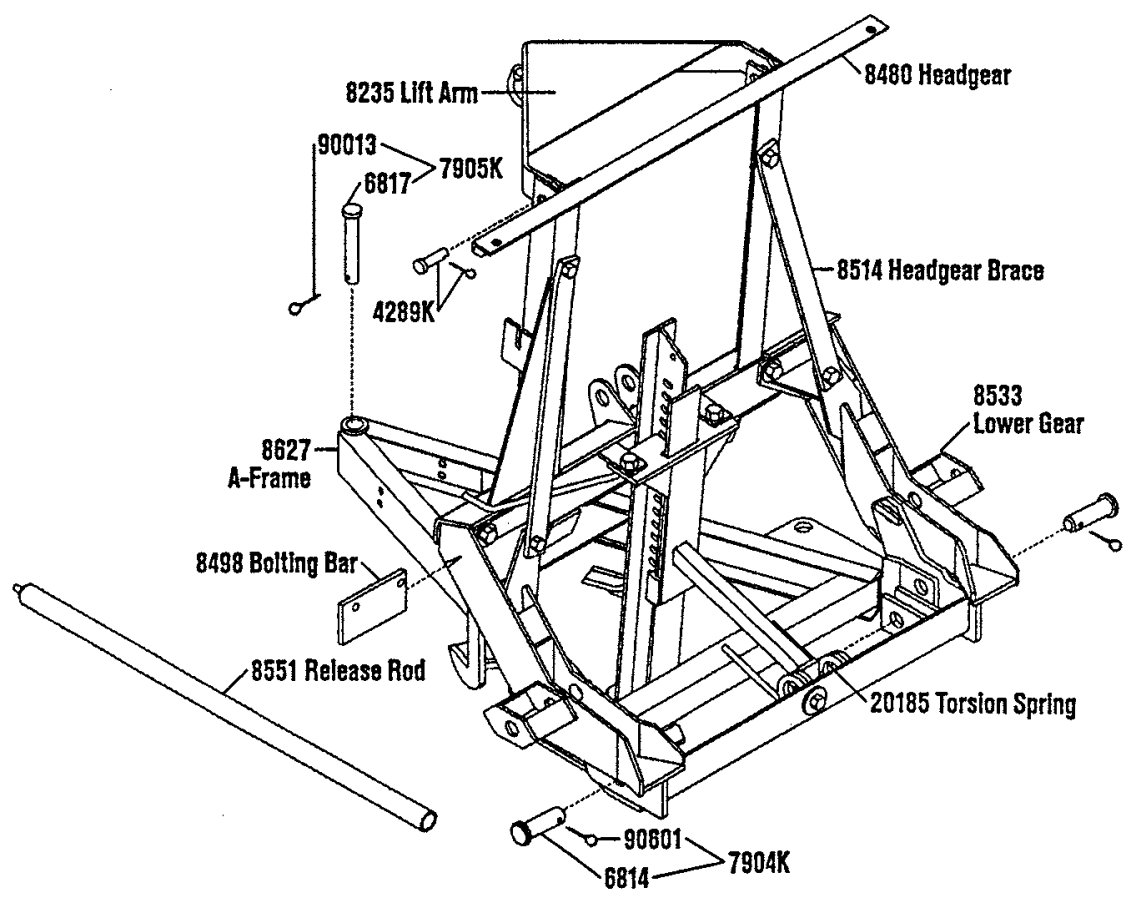




\section{REFERENCES}

Blaisdell, G.S. (1985) Measurement and evaluation of tire performance under winter conditions. Miscellaneous Paper 2387, U.S. Army Cold Regions Research and Engineering Laboratory, Hanover, New Hampshire.

Collins, N.H. (1996) SEE tractor with snowplow-Ethan Allen Training Center and Fort Drum. Unpublished field study report. U.S. Army Cold Regions Research and Engineering Laboratory, Hanover, New Hampshire.

Collins, N.H. (1997) 5-ton truck with snowplow-Fort Drum. Unpublished field study report. U.S. Army Cold Regions Research and Engineering Laboratory, Hanover, New Hampshire.

Collins, N.H. (1997) HMMWV with snowplow_Ethan Allen Training Center and Fort Drum. Unpublished field study report. U.S. Army Cold Regions Research and Engineering Laboratory, Hanover, New Hampshire.

Collins, N.H. (2000) HMMWV snowplow long-term study: 1996-2000. Unpublished report. U.S. Army Cold Regions Research and Engineering Laboratory, Hanover, New Hampshire.

Federal Highway Administration (1996) Manual of practice for an effective anti-icing program. Publication No. FHWA-RD-95-202, U.S. Department of Transportation, Washington, DC.

Ketcham, S.A., et al. (1996) Anti-icing technology. Field Evaluation Report, FHWA Test and Evaluation Project No. 28. U.S. Army Cold Regions Research and Engineering Laboratory, Hanover, New Hampshire.

Liston, R.A. (1986) Performance of highway and all-season radial tires and traction aids on ice and in snow. CRREL Special Report 86-07, U.S. Army Cold Regions Research and Engineering Laboratory, Hanover, New Hampshire.

Minsk, L.D. (1977) Freeze-thaw tests of liquid deicing chemicals on selected pavement materials. CRREL Report 77-28, U.S. Army Cold Regions Research and Engineering Laboratory, Hanover, New Hampshire.

Minsk, L.D. (1978) Current research on snow and ice removal in the United States. Miscellaneous Paper 1199, U.S. Army Cold Regions Research and Engineering Laboratory, Hanover, New Hampshire.

Minsk, L.D. (1979) Systems study of snow removal. Miscellaneous Paper 1237, U.S. Army Cold Regions Research and Engineering Laboratory, Hanover, New Hampshire. 
Minsk, L.D. (1981) Snow removal equipment. Miscellaneous Paper 1446, U.S. Army Cold Regions Research and Engineering Laboratory, Hanover, New Hampshire.

Minsk, L.D. (1987) Military snow removal problems. Miscellaneous Paper 2268, U.S. Army Cold Regions Research and Engineering Laboratory, Hanover, New Hampshire.

Sellman, P.A. (1996) Tire chains-A comparison study. Interim report, U.S. Army Cold Regions Research and Engineering Laboratory, Hanover, New Hampshire. 


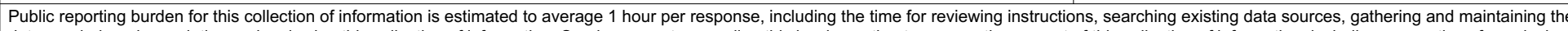

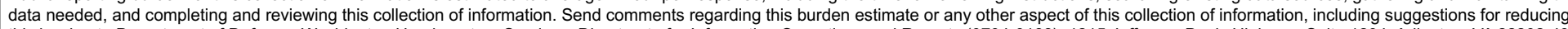

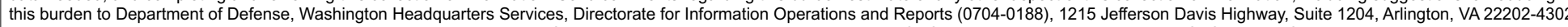

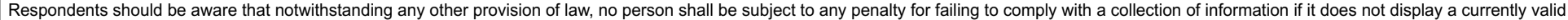
OMB control number. PLEASE DO NOT RETURN YOUR FORM TO THE ABOVE ADDRESS.
1. REPORT DATE (DD-MM-YY)
2. REPORT TYPE
May 2002
Special Report
3. DATES COVERED (From - To)

4. TITLE AND SUBTITLE

Snow and Ice Control (SNIC) Equipment

5a. CONTRACT NUMBER

and Its Use by Military Units Worldwide

5b. GRANT NUMBER

5c. PROGRAM ELEMENT NUMBER

6. AUTHOR(S)

5d. PROJECT NUMBER

Nicholas H. Collins

5e. TASK NUMBER

5f. WORK UNIT NUMBER

8. PERFORMING ORGANIZATION REPORT NUMBER

7. PERFORMING ORGANIZATION NAME(S) AND ADDRESS(ES)

U.S. Army Engineer Research and Development Center

Cold Regions Research and Engineering Laboratory

72 Lyme Road

Hanover, New Hampshire 03755-1290

ERDC/CRREL SR-02-1

9. SPONSORING/MONITORING AGENCY NAME(S) AND ADDRESS(ES)

10. SPONSOR / MONITOR'S ACRONYM(S)

HQ USAREUR

ATTN: ODSENGR

APO AE 09014

11. SPONSOR / MONITOR'S REPORT NUMBER(S)

\section{DISTRIBUTION / AVAILABILITY STATEMENT}

Approved for public release; distribution is unlimited.

Available from NTIS, Springfield, Virginia 22161.

13. SUPPLEMENTARY NOTES

14. ABSTRACT

When the U.S. Army moved into Yugoslavia in December 1995, it did so without snow and ice control (SNIC) equipment. The only available tools - the bucket loader mounted on SEE tractors, scoop loaders, full-track tractors, the M9 ACE, and the motorized road grader - were not designed for SNIC. These tools are specialized and dedicated to specific missions, and attempts to use them for SNIC proved detrimental to both the equipment and the areas requiring snow removal. Upon receipt of an urgent call from HQUSACE, it was determined that a SEE tractor snowplow prototype had been designed by the manufacturer that built and produced the SEE's front loader bucket. Within six days, the company built a SEE snowplow and shipped it to Jericho, Vermont, where it was installed on a Vermont Army National Guard (ARNG) SEE tractor. The snowplow was tested in various scenarios, at various snow depths, at temperatures as low as $-15^{\circ} \mathrm{F}$. It performed better than expected and $17 \mathrm{SEE}$ snowplows were sent to Task Force Eagle in Bosnia. Since then, snowplows for the 5-ton truck and HMMWV have been fielded to reduce the workload placed on the SEE tractor. The viability of using this equipment on various snow-covered terrain by soldiers from the 10th Mountain Division (Light Infantry) at Fort Drum, New York, and the Ethan Allen Training Center in Vermont, was demonstrated.

15. SUBJECT TERMS

$\begin{array}{lll}\text { Frozen ground } & \text { SNIC } & \text { Snowplows } \\ \text { Ice } & \text { Snow } & \text { Spreaders }\end{array}$

\begin{tabular}{|c|c|c|c|c|c|}
\hline \multicolumn{3}{|c|}{ 16. SECURITY CLASSIFICATION OF: } & \multirow{2}{*}{$\begin{array}{l}\text { 17. LIMITATION OF } \\
\text { OF ABSTRACT }\end{array}$} & \multirow{2}{*}{$\begin{array}{l}\text { 18. NUMBER } \\
\text { OF PAGES }\end{array}$} & 19a. NAME OF RESPONSIBLE PERSON \\
\hline a. REPORT & b. ABSTRACT & c. THIS PAGE & & & 19b. TELEPHONE NUMBER (include area code) \\
\hline $\mathrm{U}$ & $\mathrm{U}$ & $\mathrm{U}$ & $\mathrm{U}$ & 74 & \\
\hline
\end{tabular}




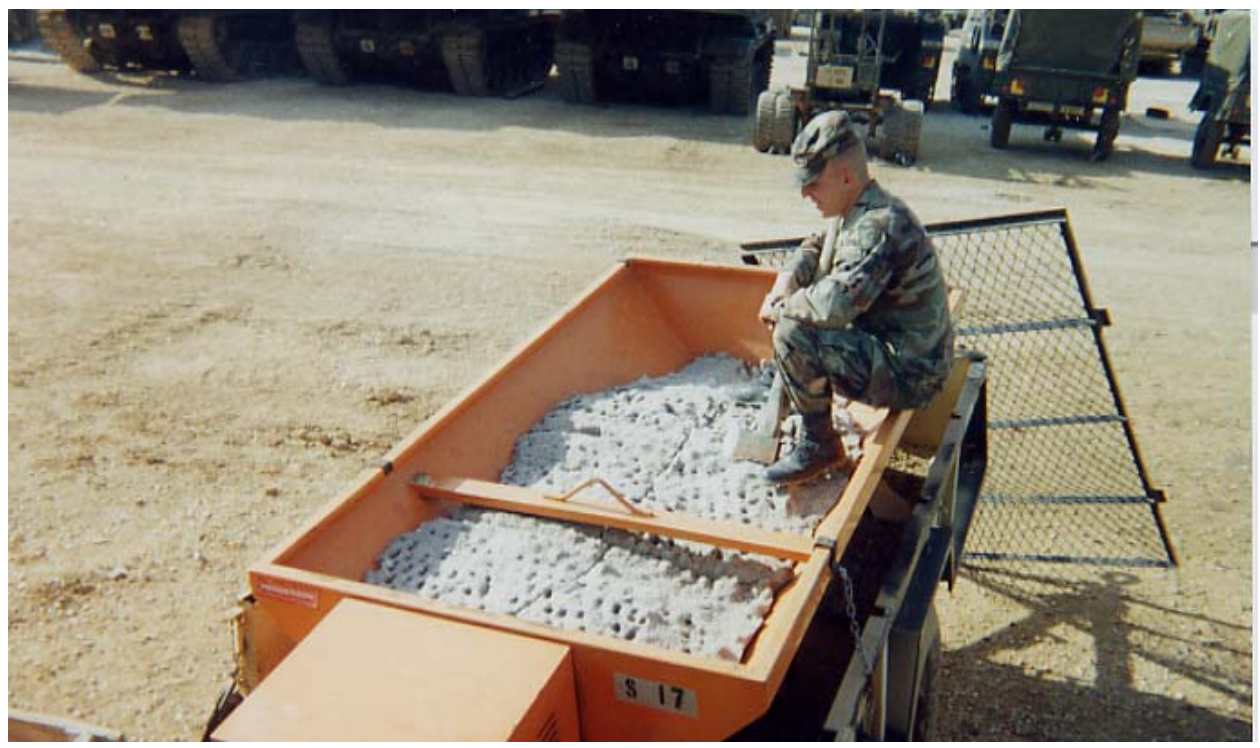

In February 2001, this Henderson spreader was filled with salt that was not used. By the time the loaded spreader was discovered in August, it had been exposed to sun and rain, as well as temperatures that reached $90^{\circ} \mathrm{F}$. The rock salt had turned to solid rock. Even the rugged soldier shown here with an axe was not able to chip off pieces larger than a peanut. It took two soldiers using steam and hot water nearly six days to melt and chip this load of solid salt out of the spreader, and several more days to loosen the movable parts and grease them for the coming winter. Never leave salt or sand/salt mixture in a spreader overnight. After each day's use, empty, wash, and relubricate the spreader.

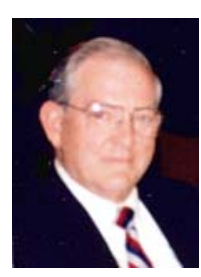

\section{About the Author}

Nicholas H. Collins, LTC, USA, (Ret) graduated from Norwich University in 1955 with a BS degree and from George Washington University in 1974 with an MS degree and is now a Physical Scientist at the U.S. Army Cold Regions Research and Engineering Laboratory (CRREL) in Hanover, New Hampshire. Colonel Collins was commissioned and entered active duty in 1955 and retired in 1984 after 29 years of service. His alternate specialty while on active duty was R\&D Coordinator, and his first R \& D assignment (1972-1976) was in the Mobility Branch , Combat Support Division, U.S. Army Materiel Systems Analysis Agency (AMSAA), where he concentrated efforts on wheeled vehicle mobility and later served as Division Chief for two years. His second R \& D assignment took him to the U.S. Army Cold Regions Research and Engineering Laboratory (1979-1982) where he served as Deputy Commander. He further concentrated on mobility R\&D, and was instrumental in the U.S. Army adoption of the Army Basic Criteria for Tires (ABCT), which remains in effect today. Upon leaving CRREL in 1982 he became the Chief, Test and Evaluation, Directorate of Combat Developments, U.S. Army Transportation School, and a year later became the Director of Combat Developments, U.S. Army Transportation School. In 1984 he worked on a contract for Martin-Marietta at Michigan Tech doing snow studies. In 1985 he was an Operations Research/Systems Analyst for FMC Corporation in San Jose, California, and worked on mobility upgrades for the M-113 and the Bradley Fighting Vehicle. In 1990, he was invited to return to CRREL as a civilian and now works as a coordinator for Military Programs. For the past seven years he has been primarily involved in the snow and ice control (SNIC) program. In this position he also fills the role of Acting PM for SNIC equipment for TACOM. 
Official Business

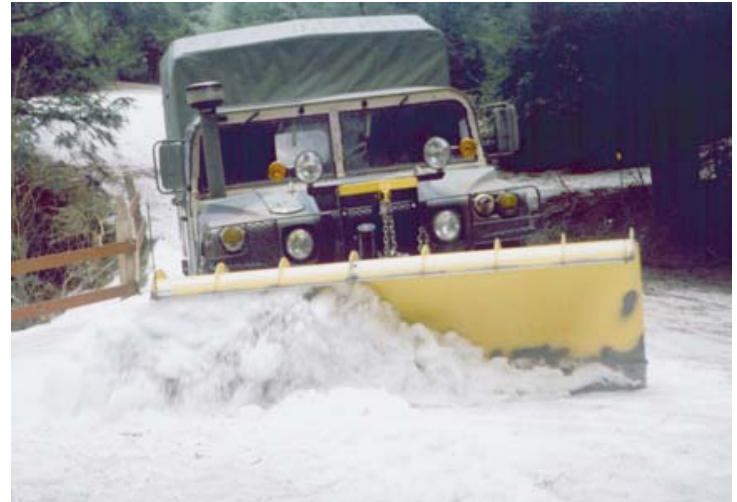

HMMWV with snowplow.

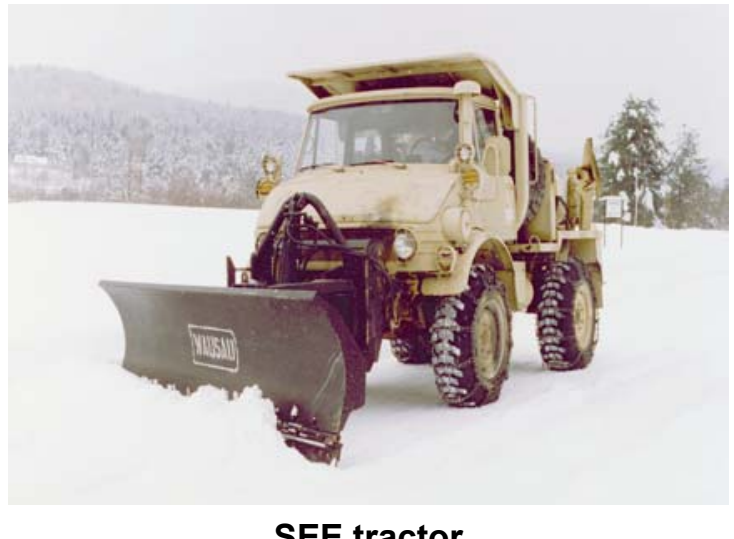

SEE tractor

with Schmidt "Wausau" brand snowplow.

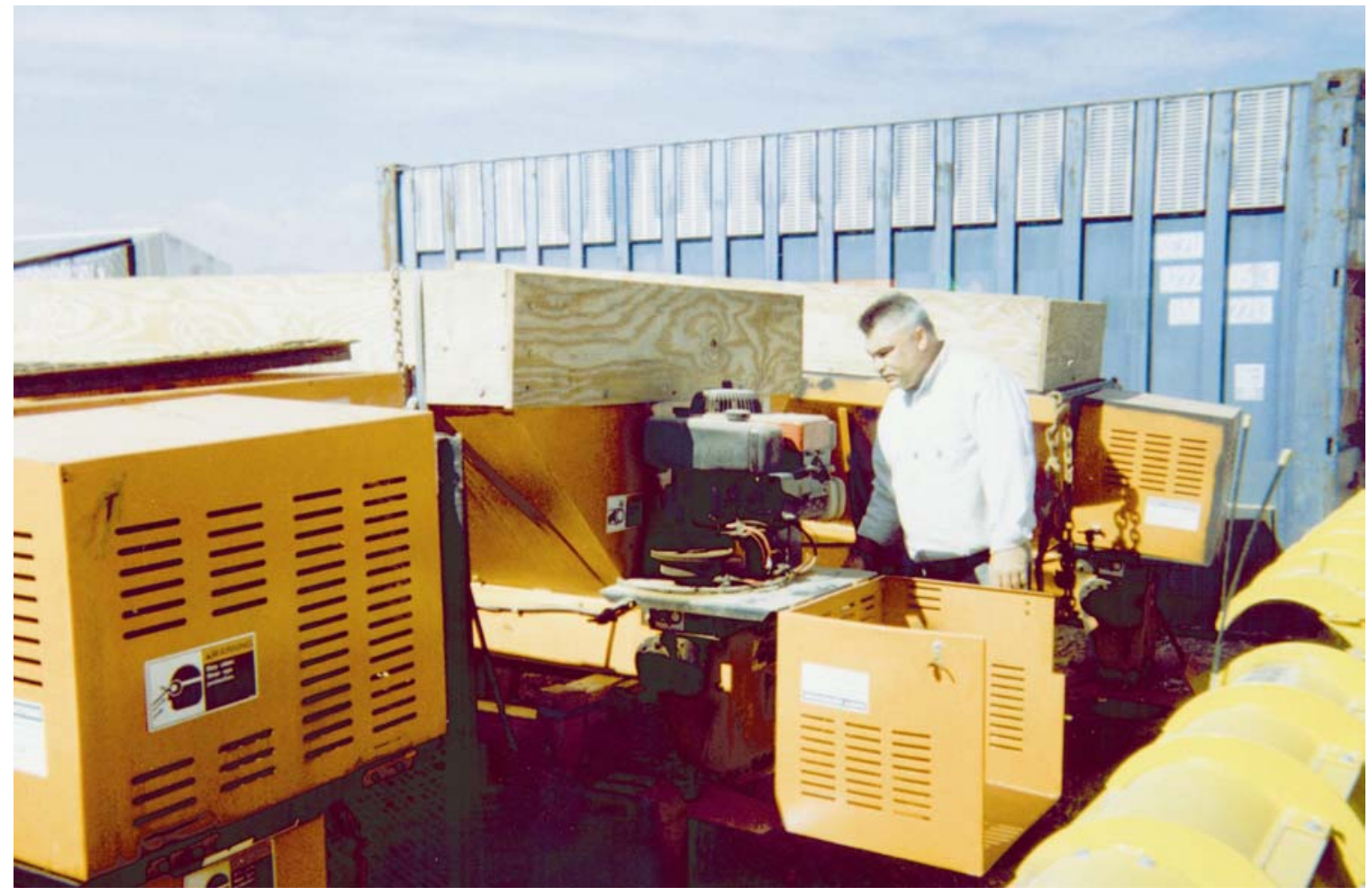

Henderson "Chief" spreader being inspected for Kosovo's winter season. Note the 12-inch extension at the top of two of the spreaders. This addition allows the 6-ft spreader's hopper capacity to increase from $1.3 \mathrm{yd}^{3}$ to $2.3 \mathrm{yd}^{3}$. On the 10-ft spreader, a 12-inch extension increases hopper capacity from $2.1 \mathrm{yd}^{3}$ to $3.8 \mathrm{yd}^{3}$. These capacities are measured at the struck (that is, level with the top of the sides of the hopper). Heaping above the grate is not recommended. 